\title{
Profiles of Instructor Responses to Emergency Distance Learning
}

\author{
Teomara Rutherford \\ University of Delaware \\ Sarah M. Karamarkovich \\ North Carolina State University
}

\begin{abstract}
Di Xu, Tamara P. Tate, Brian Sato, Rachel B. Baker, and Mark Warschauer
University of California, Irvine
\end{abstract}

\begin{abstract}
To understand instruction during the spring 2020 transition to emergency distance learning (EDL), we surveyed a sample of instructors teaching undergraduate EDL courses at a large university in the southwest. We asked them how frequently they used and how confident they were in their ability to implement each of nine promising practices, both for their spring 2020 EDL course and a time when they previously taught the same course face-to-face (F2F). Using latent class analysis, we examined how behavioral frequencies and confidence clustered to form meaningful groups of instructors, how these groups differed across F2F and EDL contexts, and what predicted membership in EDL groupings. Results suggest that in the EDL context, instructors fell into one of three profiles in terms of how often they used promising practices: Highly Supportive, Instructor Centered, and More Detached. When moving from the F2F to EDL context, instructors tended to shift "down" in terms of their profile-for example, among F2F Highly Supportive instructors, $34 \%$ shifted to the EDL Instructor Centered profile and 30\% shifted to the EDL More Detached Profile. Instructors who reported lower self-efficacy for EDL practices were also more likely to end up in the EDL More Detached profile. These results can assist universities in understanding instructors' needs in EDL, and what resources, professional development, and institutional practices may best support instructor and student experiences.
\end{abstract}

Keywords: emergency distance learning, self-efficacy, promising practices

Rutherford, T., Karamarkovich, S.M., Xu, D., Tate, T.P., Sato, B., Baker, R.B., \& Warschauer, M. (2021). Profiles of instructor responses to emergency distance learning. Online Learning, 25(1), 86-114. https://doi.org/10.24059/olj.v25i1.2472 


\section{Profiles of Instructor Responses to Emergency Distance Learning}

In March 2020, a large research-intensive university in the southwest announced that the upcoming spring quarter would move to emergency distance learning (EDL) in response to the COVID-19 pandemic. This paper focuses on how instructors responded to the EDL transition and, in particular, the extent to which they employed promising practices for online learning. To gain insight into faculty responses to the transition to EDL, we drew on literature regarding effective practices in higher education instruction, especially practices that are promising in strengthening interpersonal interactions (see e.g., Fischer et al., 2020; Jaggars \& Xu, 2016; Xu \& Xu, 2019), to create a comprehensive survey that elicited instructors' perceptions of the frequency with which they implemented and their confidence in implementing these interaction-oriented practices in both the F2F and EDL instances of their courses. Using latent class analysis, we examined how reported frequency of and confidence for practices may cluster to form meaningful groups of instructors, how these groups differ across F2F and EDL contexts, and what predicts membership in EDL groupings. By identifying relative areas of strength and weakness across contexts, universities can better discern instructor needs during EDL and online instruction and plan for professional development and other institutional supports that can improve instructor and student experiences.

\section{Review of Relevant Literature}

\section{Promising Practices in Online and F2F Contexts}

Researchers have reached consensus on two specific challenges in online teaching and learning: the need for high levels of student self-regulation (Broadbent \& Poon, 2015; Delen \& Liew, 2016; Johnson \& Davies, 2014; Kitsantas \& Dabbagh, 2004; Muilenburg \& Berge, 2005) and the difficulty of achieving effective interpersonal interactions (Bolliger \& Martin, 2018; Muilenburg \& Berge, 2005; Partlow \& Gibbs, 2003; Richardson \& Swan, 2003). To overcome these challenges, instructors may need to engage in instructional practices that create and strengthen interaction between teachers and students, such as providing clear guidance to navigate the learning process, engaging students actively throughout their learning, facilitating interpersonal interaction, and fostering social presence intentionally and visibly (Jaggars \& $\mathrm{Xu}$, 2016; Moore, 2013).

The benefits of these interaction-oriented instructional practices in the online context have been evaluated and confirmed through instructor and student perceptions. For example, based on interviews with both online students and instructors, a handful of studies indicate that strategies that enhance social interactions, especially instructor-student interactions, enable instructors to provide content-related support to students and for students to learn from each other, and alsomaybe more importantly - help to create a sense of community and belonging in an online learning environment (Kear et al., 2014; Wang, 2005; Shieh et al., 2008). A smaller but growing number of studies establish an empirical link between instructional practices and student learning outcomes. For example, Jaggars and Xu (2016) grouped online instructional practices that have been advocated by various online quality rubrics into four main areas and found that instructional practices that facilitate high quality student-instructor and student-student interactions relate positively to student course grades. 
The promise of interaction-oriented practices in online learning is in line with literature in the F2F context that has reached consensus on the benefits of highly interactive in-person environments for learning. In particular, evidence suggests that student-centered or active learning instruction improves academic outcomes for undergraduates (Deslauriers et al., 2011; Freeman et al., 2007; Freeman et al., 2014; PCACT, 2012), particularly for minoritized populations that often face greater challenges than their more privileged peers (Eddy \& Hogan, 2014). Hallmarks of student-centered instruction include the incorporation of peer-to-peer interaction into the lecture period and opportunities for students to reflect on their understanding of a particular concept.

In addition to interpersonal interaction, scholars of online learning have also emphasized the importance of student interaction with content (Murray et al., 2012; Nandi et al., 2015). Such interactions can be facilitated by well-structured courses that provide opportunities for formative feedback; examples might include pre-lecture reading quizzes to ensure that textbook readings are accomplished prior to attending class, regular problem sets to provide ample, low-stakes assessment opportunities for students, and multiple high-stakes exams as opposed to a single midterm and final (e.g., McDaniel et al., 2012). These practices may be especially important for STEM courses - a committee of the National Research Council highlight formative feedback along with collaborative and interactive learning as promising practices for successful undergraduate education (Singer et al., 2012).

Overall, the literature points to nine interaction-oriented practices that may be particularly beneficial for online learning-providing formative feedback, providing opportunities for collaborative work, providing practice opportunities, conveying personality and humanity, encouraging students to get to know each other, giving reminders, assisting with the learning management system (LMS), encouraging student reflection, and answering questions (Fischer et al., 2020; Jaggars \& Xu, 2016; Xu \& Xu, 2019). Given the critical role that these practices play in both online and F2F settings, we focus on these practices in this paper as "promising practices."

\section{The Prevalence of These Practices}

Despite the increasing evidence for the value of these practices, their implementation has yet to occur on a large scale in higher education institutions (e.g., Ebert-May et al., 2011; Henderson \& Dancy, 2007; Stains et al., 2018). A handful of studies have collected information on faculty reported use of online instructional practices (e.g., Hutti, 2007; Tirrell and Quick, 2012; Zhang, 2006); among these, Tirrell and Quick (2012) is particularly relevant to the current study. Drawing on survey responses from 111 faculty members who taught at least one online course at three community colleges in Virginia, the authors found that instructors reported frequently using teaching practices that are commonly expected in traditional F2F instruction, such as "setting clear expectations" and "encouraging students to ask questions when they don't understand" (p. 585). In contrast, faculty reported limited use of practices and teaching strategies that are tailored and can be particularly useful in online learning, such as creating learning communities and promoting self-regulated learning by having students direct learning activities. Similarly, Avery and colleagues (2008) evaluated 16 online courses and found that some instructional practices, such as articulating the connection between course objectives and learning activities and specifying the skills and knowledge necessary for the courses, were reported less often than other practices.

There are many reasons for instructors' nonoptimal engagement in these promising practices, including a lack of effective professional development (Andrews \& Lemons, 2015; Henderson et al., 2011), institutional cultures which prioritize research excellence over teaching 
excellence (Aplay \& Verschoor, 2014; Cadez et al., 2007), and student resistance to studentcentered pedagogies (Deslauriers et al., 2019; Henderson et al., 2012). In addition to examining institutional contributors or barriers to change, research has identified characteristics of instructors who are more or less likely to implement evidence-based practices. Henderson et al. (2012) conducted a nationwide survey of physics instructors and found that those who implement interactive teaching practices are more likely to be familiar with education research, have attended instructional professional development workshops, be in a permanent, full-time position, and be female. Walter et al. (2017) collected self-reported survey data about instructional practices and found that courses with smaller enrollments and those taught by female instructors were more likely to be classified as student-centered, whereas other demographic characteristics, such as STEM or non-STEM discipline and faculty position, were not predictive of instructional type. Stains et al. (2018) collected classroom observation data from 24 institutions across North America and found unique instructional profiles based on course enrollment and discipline. Using cluster analysis to characterize their data set, they identified seven unique clusters that they classified under three instructional profiles, didactic, interactive lecture, and student-centered. To date, no studies have examined the prevalence of these practices as used by the same instructors across both F2F and online contexts, and how instructor characteristics and context contribute to instructor use of these practices. We investigate the extent to which instructors report using interaction-oriented practices, focusing on those between instructors and students, students and peers, and students and the course content.

\section{Instructor Self-Efficacy}

One important determinant of instructor practices is their confidence or self-efficacy for successfully carrying out those practices (Bandura, 1997; Tschannen-Moran et al., 1998). This confidence in ability has been linked to instructor effort, persistence, and success (e.g., Chestnut \& Burley, 2015; McDavid et al., 2018; Rutherford et al., 2017). For example, based on survey responses from approximately 130 online instructors at a large community college, Orona et al. (2020) found that instructors with greater self-efficacy for online instruction and in using online platforms used interaction-oriented practices more frequently in their online classes to promote student engagement. As the instructional challenges between online and F2F contexts differ (Cavanaugh, 2005), it is likely that even within instructor, self-efficacy will differ for teaching online and F2F. This difference has been reflected in the measures used to investigate online instructor self-efficacy. Robinia and Anderson (2010) modified an instrument created for the F2F K-12 classroom context by Tschannen-Moran and Hoy (2001) into one for the online context, focusing on nurse educators. Their 32-item instrument measured self-efficacy along four dimensions: student engagement, instructional strategies, classroom management, and use of computers. Although many of the question types overlapped between the F2F and online instruments, the Robinia and Anderson (2010) instrument referred specifically to the online context; it would therefore be difficult to use this or a similar instrument to compare between online and F2F contexts. Instead, we focus our investigation of self-efficacy on promising interaction-oriented practices that can apply across contexts. Further, instructor self-efficacy reflects the multidimensional nature of instructor practices, and although there has been little research investigating self-efficacy using methods that allow for this multidimensionality, recent research has found support for profiles of self-efficacy with differing levels of confidence across practices (e.g., Perera et al., 2019). 
Self-efficacy is itself informed by instructor background characteristics and experiences; gender, discipline, rank, and experience-including experience teaching online-have shown relations with self-efficacy (Chang et al., 2011; Horvitz et al., 2015; Vang et al., 2020). In particular, Martin and colleagues (2019) found that faculty who had only taught F2F had lower self-efficacy for teaching online. There is overlap between these factors that influence self-efficacy and ones that influence instructor practice (e.g., Henderson et al., 2012); we examine some of these antecedents within our study.

\section{Current Study}

The pandemic and the switch to EDL across universities brings comparisons of online and F2F instruction into sharp relief. In this study, we focus on a large university in the southwest which offers classes on the quarter system. The university's shift to remote learning was announced the week prior to winter quarter final examinations, and two weeks before the spring quarter was scheduled to begin. Instructors, many of whom had not previously taught online, scrambled to translate their planned F2F courses into distance formats. Understanding which practices they engaged in across these contexts and how confident they felt in their ability to successfully carry out these practices can provide insight into both student and instructor experiences during EDL in higher education and can reveal opportunities and challenges toward strengthening instructor practices across contexts. With the current study, we survey a sample of university instructors teaching a course in an EDL format that they had previously taught F2F. We ask: (1) What profiles of frequency of and confidence in promising practices emerge in both F2F and EDL courses? (2) What predicts membership in EDL frequency profiles?

\section{Methods}

\section{Participants and Context}

Participants were drawn from instructors who, at the close of the spring 2020 quarter, were teaching a large undergraduate course online with at least 50 students enrolled and who had previously taught the same course $\mathrm{F} 2 \mathrm{~F}(\mathrm{~N}=374)$ according to administrative records. The data did not differentiate between tenure-track, teaching, and graduate student instructors, so we included a screening question into our survey. Invitations to complete a survey were sent via email with follow-up reminders during a two-week period. Each instructor who completed the survey was compensated with a \$50 gift card. A total of $222(59 \%)$ instructors started the survey, some of whom were screened out for not being lecturers or tenure-track faculty or because they reported having not previously taught the class F2F. Of those 222, 137 instructors (36\% of 374) fully responded to the survey and were in the analysis sample. Because of instructor privacy concerns, we have not been able to get administrative or demographic information on the population of instructors who taught large classes in spring 2020 and in prior terms, nor additional demographics on those who answered our survey beyond the survey questions.

Our analysis sample taught an average of 1.48 classes online before spring 2020 (SD = 2.99 ) with $68 \%$ never having taught online before. Thirty-nine percent were women, $32 \%$ were in a STEM department, and the majority were tenure-track research faculty (55\%; an additional 17\% were tenure-track teaching faculty who focus primarily on teaching but can earn security of employment, and the remaining $28 \%$ were lecturers). Slightly less than half (48\%) of the instructors reported that needing to care for family impacted their EDL teaching. The sample of 
137 was reasonably representative of the overall university population of approximately 1,600 academic instructors, which comprises $39 \%$ women, with $41 \%$ teaching in a STEM department, and $75 \%$ on a research or teaching tenure track.

\section{Measures}

The survey was designed to provide insight into instructors' experiences with EDL in spring 2020. It was given after the spring 2020 quarter and most questions were framed to retrospectively examine the EDL experience, with others covering background factors and prior experiences teaching the same course F2F. Before completing any questions relating to instruction, respondents were asked to select the course to which they would be referring from a drop-down menu of their courses that met the requirements ( 50 or more students, taught previously F2F). The survey was administered via Qualtrics; questions referencing the target course auto-populated with the course number from the respondent's drop-down selection.

\section{Target Questions}

The survey focused on nine promising practices: Collaborative Work ("Provide opportunities for collaborative work (e.g., group assignments, peer review))"; Encourage Relationships ("Encourage students to get to know each other more than what was required to complete assignments and tasks"); Assist with LMS ("Assist students in managing the LMS and other learning technology"); Formative Feedback ("Provide formative feedback to students on assignments (e.g., ungraded or low-stakes opportunities to promote and measure student knowledge and skills")); Practice Opportunities ("Provide practice opportunities (e.g., quizzes, problem-sets, other assignments")); Encourage Reflection ("Encourage students to reflect on their learning"); Convey Personality ("Try to convey your humanity and individual personality in communications with students (e.g., using humor, pictures of your pet, videos of yourself")); Give Reminders ("Give reminders to students about course content and assignments (e.g., weekly checkins, announcements")); and Answer Questions ("Answer student questions about learning material (e.g., responding to content-related questions)."

The survey asked each respondent to report both the frequency with which they engaged in each practice and their confidence in successfully carrying out these practices, separately for the spring 2020 (EDL) course and for when they had taught the course F2F in the past. In terms of frequency, options were: never, one or two times a quarter, once a month, once a week, or multiple times most weeks. In terms of confidence, options were: not at all confident, not very confident, neither confident nor not confident, confident, very confident. See Tables 1 and 2 for summaries of responses to these questions.

\section{Instructor Background Characteristics}

To capture background characteristics which may influence teaching practices, we used administrative data to determine previous experience teaching online (DL Experience) and whether the instructor was in a STEM department (STEM), and collected survey data on instructor classification (lecturer, tenure-track teaching faculty, or tenure-track research faculty), and whether the instructor reported that needing to care for family impacted their EDL teaching (Family Care). We gathered gender information by observing instructors' visual appearance and self-identification in their online presence (e.g., university website); gender was coded independently by two researchers, with a third breaking any disagreements. We chose to gather gender information because of the relation between gender and instructor practices and self- 
efficacy (e.g., Chang et al., 2011; Henderson et al., 2012; Horvitz et al., 2015) and because of evidence that women academics have been disproportionately impacted by the pandemic (Yildirim et al., 2020). We had planned to collect this and other information from university records, but due to time constraints, had to rely on researcher coding. Intercorrelations between background characteristics were typically weak and non-statistically-significant, with the exceptions that men were more likely to teach in STEM departments $(\mathrm{r}=0.26, p=.002)$, lecturers were more likely to have prior online teaching experience whereas tenure-track research faculty were less likely (respectively, $\mathrm{r}=0.27, p=.001 ; \mathrm{r}=-0.27, p=.001$ ); and instructors in STEM were more likely to be on the teaching tenure track $(\mathrm{r}=0.19, p=.024)$.

\section{Analyses}

\section{Latent Class Analysis-Question 1: What profiles of frequency of and confidence in promising practices emerge in both F2F and EDL courses?}

For this research question, we use latent class analysis (LCA) to identify patterns of instructor practices and place instructors into profiles. LCAs are used to identify patterns of responses in data, including ordinal data such as our measures (Hagenaars \& McCutcheon, 2002; Nylund et al., 2007). Such patterns can better represent how behaviors function within a person, instead of examining variables as if they exist independently of other variables (Collins \& Lanza, 2010). With the target variables, we ran four separate LCAs: EDL frequencies, EDL confidence, $\mathrm{F} 2 \mathrm{~F}$ frequencies, and F2F confidence. Instructor membership in a profile for one category of variables (e.g., EDL frequency) did not influence their membership in a profile for another category (e.g., F2F frequency). Models with $k$ versus $k+1$ classes were tested iteratively to determine the most appropriate number of classes. To determine best fit, sample size adjusted Bayesian Information Criterion (BIC), entropy, and the bootstrap likelihood ratio test (BLRT) were used (Nylund et al., 2007). These tests attempt to determine the number of classes that will maximize similarity within groups while maximizing differences across groups. If there were similar fit indices, theoretical interpretability and the number of parameters were used to select the number of profiles with the best fit.

LCAs have two outputs - the nominal class variable and classification probabilities for each class for each individual (also known as posterior probabilities). These classification probabilities give the likelihood that a person belongs to each profile (Collins \& Lanza, 2010). Take, for example, a three class solution. A person may have a 75\% likelihood of being in Class 1, a $25 \%$ likelihood of being in Class 2 , and a $0 \%$ likelihood of being in Class 3 . The nominal class variable would say that this person belongs to Class 1 ; however, this does not take into account the $25 \%$ of uncertainty. We use these classification probabilities to answer our second research question - what predicts membership in EDL frequency profiles.

\section{Regression Analysis-Question 2: What predicts membership in EDL frequency profiles?}

Using the probability of profile membership identified in the LCAs, we then ran two types of Ordinary Least Squares (OLS) regressions to examine predictors of EDL frequency profile membership. The first was a hierarchical linear regression with three models where in step one, EDL frequency profile membership probabilities were regressed on instructor background characteristics. Then, in step two, F2F frequency profiles were added. Lastly, in step three, EDL confidence profiles were added. Profiles were included as a series of dummy variables for N-1 profiles where $\mathrm{N}$ is the number of profiles. The coefficient for each profile represents the association between that profile and the outcome as compared to the reference profile (the one left 
out of the regression). We conducted post-hoc Ward's $F$ tests to compare the coefficients of the profiles in the regression. For example, if a three class solution was selected and Class 1 was the reference profile, the regression coefficients represent the association between Class 2 (as compared to Class 1) and the outcome, as well as Class 3 (as compared to Class 1) and the outcome. To compare the association of the outcome to Class 2 and Class 3, post-hoc tests (i.e., Ward's $F$ ) must be conducted. Using hierarchical linear regressions allows us to understand the amount of unique variance explained by each additional step. For example, at step two, we can identify the amount of variance F2F frequency profiles explain in EDL frequency profile membership, above and beyond the effects of instructor background characteristics. Wald's $F$ post-hoc tests were used to test for differences between profiles included in the regression. Results from these analyses would provide information on which background characteristics, EDL self-efficacy profile, and $\mathrm{F} 2 \mathrm{~F}$ practices predicted the instructor's likelihood of being in a given EDL frequency profile compared to both other profiles together.

Although profile membership provides valuable information on how levels of practices actually coexist within instructors, a variable-centered approach may contribute different explanatory information. In particular, we examined how reported frequencies of specific F2F practices (e.g., providing formative feedback) predicted EDL frequency profiles. This provides information on how a specific practice predicts EDL frequency profile, controlling for all other practices.

We use classification probabilities in both sets of regressions. We chose to use the classification probabilities, instead of profile membership, for two reasons. First, using classification probabilities accounts for uncertainty in profile membership (Collins, 2001; Collins \& Lanza, 2010). Second, OLS models are easier to understand and interpret compared to the multinomial logistic regressions required to properly analyze this type of multinomial categorical outcome. However, in order to confirm our results were not sensitive to analysis type, we also ran multinomial logistic models, which provided similar results. Due to the superior simplicity and interpretability of the OLS models, we present results from OLS models below.

\section{Results}

\section{Descriptive Results for Frequencies and Confidence}

Tables 1 and 2 present descriptive statistics on instructor responses to the frequency and confidence questions. Intercorrelations between specific behaviors' frequencies were typically statistically significant $(60 \%)$ but mild in size, with $19 \%$ having a correlation greater than 0.30 . In the F2F context, the largest relationships were between Give Reminders and Answer Questions ( $\mathrm{r}$ $=0.44, p<.001)$, and between Encourage Relationships and Convey Personality $(\mathrm{r}=0.39, p<$ $.001)$. In the EDL context, the largest relationships were between Formative Feedback and Practice Opportunities $(\mathrm{r}=0.38, p<.001)$, and between Answer Questions and Encourage Reflections $(\mathrm{r}=$ $0.38, p<.001)$. 
Table 1

Frequencies of Instructor Practices

\begin{tabular}{|c|c|c|c|c|c|c|}
\hline & & Never & $\begin{array}{c}\text { Once or twice a } \\
\text { quarter }\end{array}$ & $\begin{array}{l}\text { Once a } \\
\text { month }\end{array}$ & $\begin{array}{c}\begin{array}{c}\text { Once a } \\
\text { week }\end{array} \\
\end{array}$ & $\begin{array}{c}\text { Multiple times } \\
\text { most weeks }\end{array}$ \\
\hline Collaborative & Spring 2020 & $49 \%$ & $17 \%$ & $4 \%$ & $21 \%$ & $9 \%$ \\
\hline Work & Face-to-Face & $24 \%$ & $16 \%$ & $9 \%$ & $26 \%$ & $25 \%$ \\
\hline Encourage & Spring 2020 & $39 \%$ & $26 \%$ & $10 \%$ & $18 \%$ & $7 \%$ \\
\hline Relationships & Face-to-Face & $17 \%$ & $8 \%$ & $12 \%$ & $35 \%$ & $28 \%$ \\
\hline Assist with & Spring 2020 & $22 \%$ & $20 \%$ & $20 \%$ & $20 \%$ & $18 \%$ \\
\hline$L M S$ & Face-to-Face & $30 \%$ & $19 \%$ & $20 \%$ & $16 \%$ & $15 \%$ \\
\hline Formative & Spring 2020 & $15 \%$ & $15 \%$ & $10 \%$ & $38 \%$ & $23 \%$ \\
\hline Feedback & Face-to-Face & $8 \%$ & $10 \%$ & $13 \%$ & $40 \%$ & $29 \%$ \\
\hline Practice & Spring 2020 & $13 \%$ & $10 \%$ & $11 \%$ & $42 \%$ & $24 \%$ \\
\hline Opportunities & Face-to-Face & $13 \%$ & $9 \%$ & $21 \%$ & $31 \%$ & $26 \%$ \\
\hline Encourage & Spring 2020 & $39 \%$ & $26 \%$ & $10 \%$ & $18 \%$ & $7 \%$ \\
\hline Reflection & Face-to-Face & $17 \%$ & $8 \%$ & $12 \%$ & $35 \%$ & $28 \%$ \\
\hline Convey & Spring 2020 & $9 \%$ & $14 \%$ & $10 \%$ & $20 \%$ & $47 \%$ \\
\hline Personality & Face-to-Face & $2 \%$ & $7 \%$ & $6 \%$ & $18 \%$ & $68 \%$ \\
\hline Give & Spring 2020 & $1 \%$ & $2 \%$ & $8 \%$ & $45 \%$ & $45 \%$ \\
\hline Reminders & Face-to-Face & $1 \%$ & $1 \%$ & $7 \%$ & $38 \%$ & $54 \%$ \\
\hline Answer & Spring 2020 & $0 \%$ & $2 \%$ & $4 \%$ & $27 \%$ & $67 \%$ \\
\hline Questions & Face-to-Face & $0 \%$ & $0 \%$ & $4 \%$ & $15 \%$ & $81 \%$ \\
\hline
\end{tabular}

Note. $\mathrm{N}=137$. Most common response for each practice is bolded and italicized.

Table 2

Confidence in Instructor Practices

\begin{tabular}{llccccc}
\hline & Not at all & $\begin{array}{c}\text { Not very } \\
\text { confident }\end{array}$ & $\begin{array}{c}\text { Neither } \\
\text { confident } \\
\text { nor not }\end{array}$ & Confident & $\begin{array}{c}\text { Very } \\
\text { confident }\end{array}$ \\
\hline Collaborative & Spring 2020 & $15 \%$ & $23 \%$ & $\mathbf{2 3 \%}$ & $23 \%$ & $15 \%$ \\
Work & Face-to-Face & $3 \%$ & $4 \%$ & $24 \%$ & $26 \%$ & $\mathbf{4 3 \%}$ \\
Encourage & Spring 2020 & $19 \%$ & $23 \%$ & $\mathbf{2 9 \%}$ & $17 \%$ & $12 \%$ \\
Relationships & Face-to-Face & $4 \%$ & $7 \%$ & $22 \%$ & $29 \%$ & $\mathbf{3 8 \%}$ \\
Assist with & Spring 2020 & $5 \%$ & $9 \%$ & $26 \%$ & $26 \%$ & $\mathbf{3 4 \%}$ \\
LMS & Face-to-Face & $11 \%$ & $4 \%$ & $30 \%$ & $22 \%$ & $\mathbf{3 3 \%}$ \\
Formative & Spring 2020 & $6 \%$ & $8 \%$ & $16 \%$ & $\mathbf{3 7 \%}$ & $33 \%$ \\
Feedback & Face-to-Face & $2 \%$ & $4 \%$ & $7 \%$ & $31 \%$ & $\mathbf{5 8 \%}$ \\
Practice & Spring 2020 & $2 \%$ & $4 \%$ & $12 \%$ & $36 \%$ & $\mathbf{4 6 \%}$ \\
Opportunities & Face-to-Face & $1 \%$ & $4 \%$ & $13 \%$ & $25 \%$ & $\mathbf{5 7 \%}$ \\
Encourage & Spring 2020 & $1 \%$ & $7 \%$ & $20 \%$ & $29 \%$ & $\mathbf{4 4 \%}$ \\
Reflection & Face-to-Face & $0 \%$ & $3 \%$ & $18 \%$ & $28 \%$ & $\mathbf{5 2 \%}$ \\
Convey & Spring 2020 & $4 \%$ & $8 \%$ & $13 \%$ & $31 \%$ & $\mathbf{4 4 \%}$ \\
Personality & Face-to-Face & $2 \%$ & $2 \%$ & $8 \%$ & $25 \%$ & $\mathbf{6 4 \%}$ \\
Give & Spring 2020 & $0 \%$ & $2 \%$ & $7 \%$ & $26 \%$ & $\mathbf{6 5 \%}$ \\
Reminders & Face-to-Face & $0 \%$ & $0 \%$ & $4 \%$ & $23 \%$ & $\mathbf{7 2 \%}$ \\
Answer & Spring 2020 & $0 \%$ & $0 \%$ & $4 \%$ & $20 \%$ & $\mathbf{7 6 \%}$ \\
Questions & Face-to-Face & $0 \%$ & $0 \%$ & $4 \%$ & $15 \%$ & $\mathbf{8 1 \%}$ \\
\hline
\end{tabular}

Note. $\mathrm{N}=137$. Most common response for each practice is bolded and italicized. 


\section{Latent Class Analysis-Question 1: What profiles of frequency of and confidence in promising practices emerge in both F2F and EDL courses?}

For all four sets of LCAs, three profiles were selected as best fit (Appendix A). The bootstrap likelihood ratio test suggested that the three class solutions were always statistically significantly better than the two class solutions $(p<.001)$. For the EDL confidence, F2F frequency, and F2F confidence profiles, the four class solution provided slightly better fit. However, the four profile solutions were less theoretically interpretable than the three class solutions and often were not replicated (i.e., the best-fitting model differed when analyses were repeated). Additionally, the four class F2F frequency solution had a higher number of parameters (139) than our sample size (137), making the model unidentifiable. Using the sample-size adjusted BIC, the three class models were past the "elbow," which indicated that the any further decrease in the sample-size adjusted BIC was past the "point of 'diminishing returns' in model fit" (Nylund-Gibson \& Choi, 2018, p. 443). Therefore, the three profile solutions were selected.

\section{EDL Profiles}

We characterize the three EDL frequency profiles as Highly Supportive, Instructor Centered, and More Detached. Instructors in the Highly Supportive profile (27\%) reported the highest frequencies of all practices. The Instructor Centered profile (21\%) had instructors that conveyed their personalities and supported students by giving reminders and answering questions. However, they did not provide opportunities for collaborative work or encourage students to develop relationships with other students, nor did they provide formative feedback as frequently as the instructors in the Highly Supportive profile. The largest EDL frequency profile was More Detached (52\%). These instructors reported low frequencies for most practices, other than answer questions and give reminders.

Figure 1 displays each EDL frequency profile as a separate series of bar charts. The percentage of instructors within each profile reporting a given frequency for each practice is represented by the shaded blocks in each bar. For example, $90 \%$ of instructors in the Highly Supportive profile reported giving formative feedback at least once a week (the combination of "once a week" and "multiple times most weeks" responses). In contrast, only around 50\% of instructors reported giving formative feedback at least once a week in both the Instructor Centered

and More Detached profiles. Appendix E displays the average difference in frequency of each practice by profile for both EDL and F2F frequency profiles. 


\section{Figure 1.}

\section{Spring 2020 (Emergency Distance Learning) frequency of practices.}

Highly Supportive (27\%)

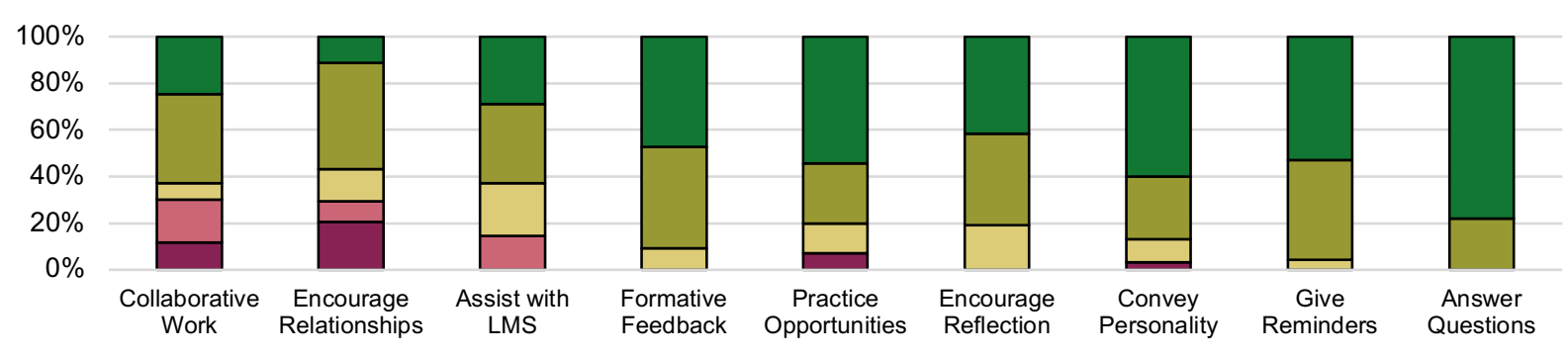

Instructor Centered (21\%)

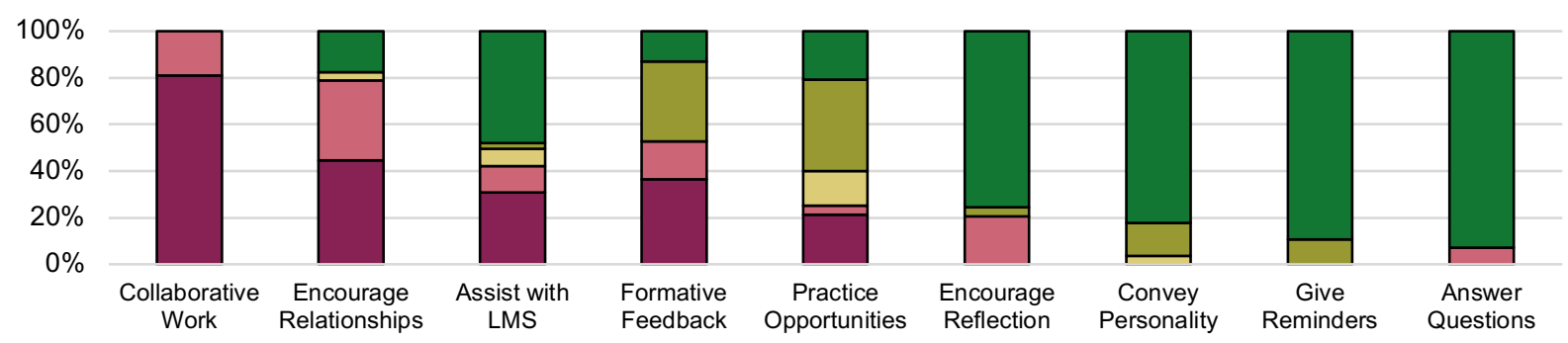

More Detached (52\%)

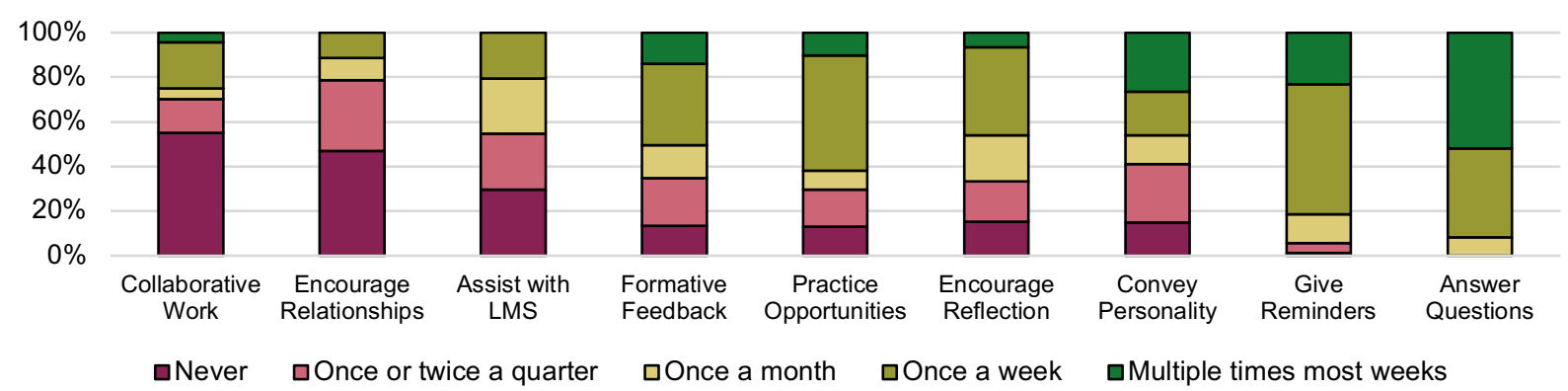

The EDL confidence profiles were characterized as Higher Confidence, Mid Confidence, and Lower Confidence (Figure 2). The Higher Confidence profile was the largest (49\%); within this profile a high percentage of instructors reported they were confident or very confident in their ability to successfully complete nearly all practices. Instructors in the Mid Confidence profile (31\%) were less confident than those in the Higher Confidence profile, but still were mostly confident in their ability. Instructors in the Lower Confidence profile (20\%) mostly reported that they were "neither confident nor not confident" in most practices. In contrast to the frequency profiles, confidence profiles exhibited few qualitative differences in patterns of responses across practices. For example, instructors reported lower confidence for both facilitating collaborative work and encouraging relationships across profiles, although the relative confidence in these practices still followed the higher/mid/lower pattern seen for other practices. 


\section{Figure 2.}

\section{Spring 2020 (Emergency Distance Learning) confidence in practices.}

Higher Confidence (49\%)

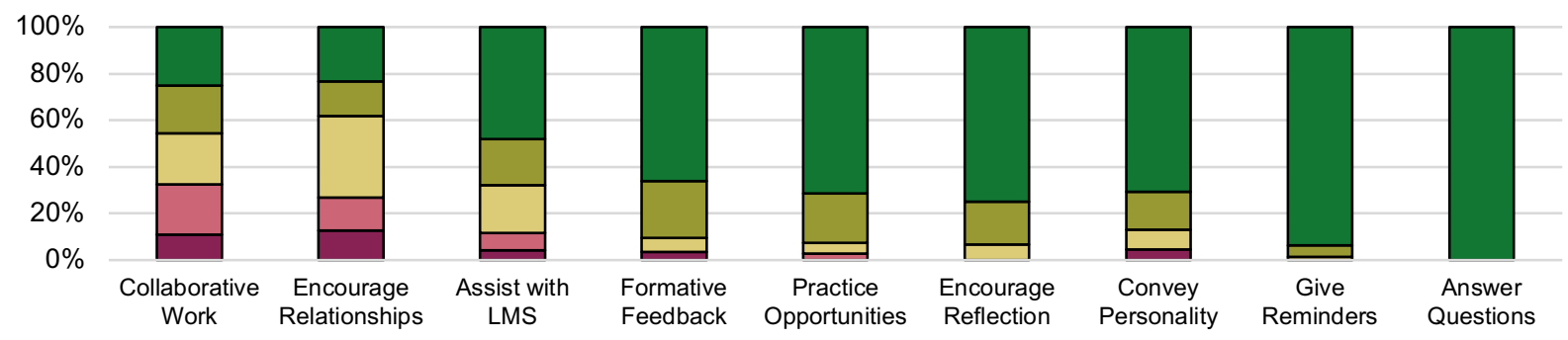

Mid Confidence (31\%)

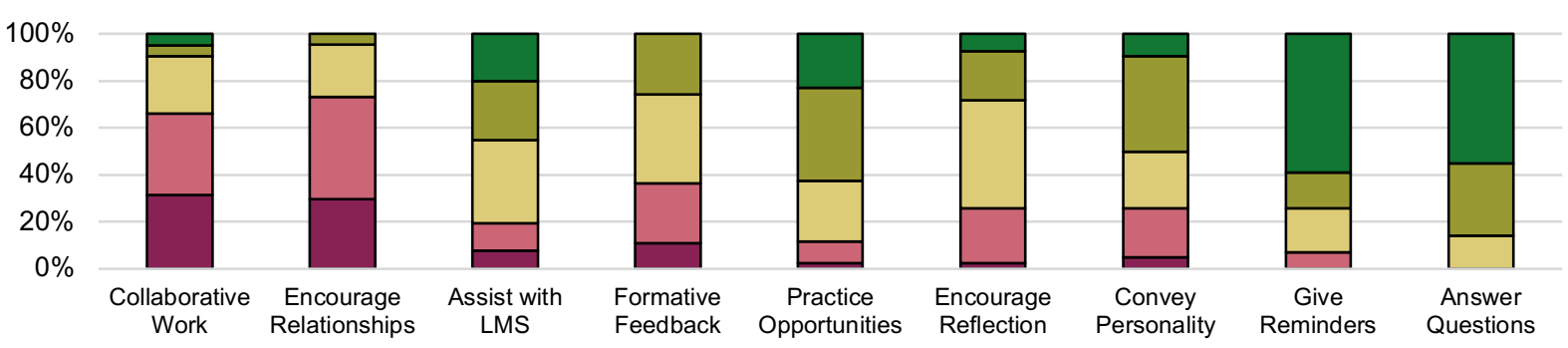

Lower Confidence (20\%)

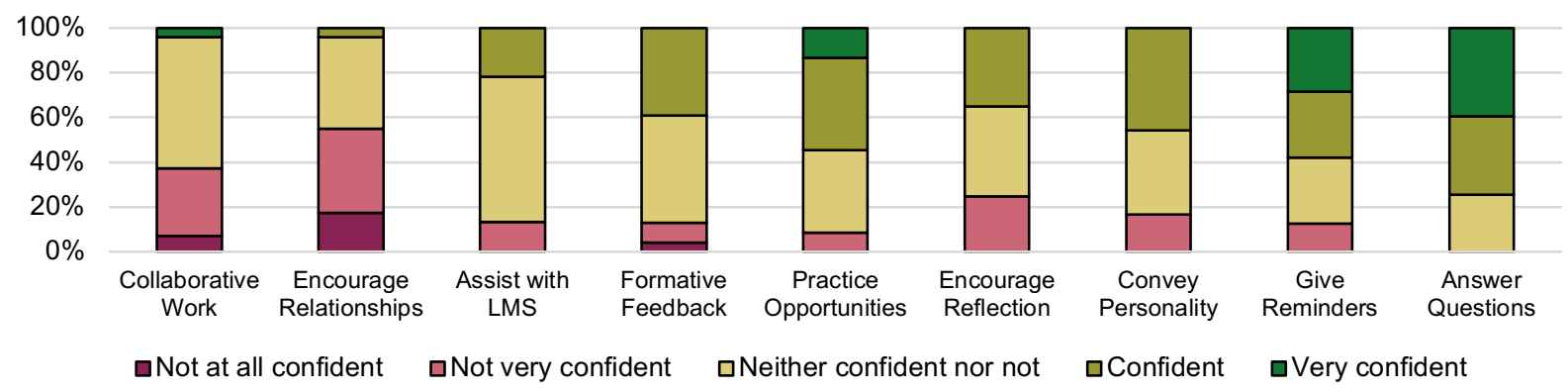

\section{F2F Profiles}

Two profiles similar to those in the EDL analyses were found with the F2F frequency questions-Highly Supportive and Instructor Centered (Figure 3). Like the EDL frequency profiles, those in the Highly Supportive profile (32\%) reported the highest frequency of all practices. In the Instructor Centered profile (30\%), more instructors reported that they would frequently convey personality, give reminders, and answer questions; few reported they would often give collaborative work, encourage relationships, or assist with the LMS. One distinguishing feature between F2F and EDL Instructor Centered profiles is the reported frequency of LMS assistance. Instructors classified as belonging to the EDL Instructor Centered profile reported providing more frequent assistance than those within the F2F Instructor Centered profile. More instructors belonged to the Highly Supportive and Instructor Centered profiles for F2F classes than for EDL classes (Highly Supportive had 17 more instructors, Instructor Centered had 15 more instructors). The third F2F profile, Somewhat Supportive profile (38\%), differed from the third EDL profile, More Detached, in that it was not as extreme. Membership in either EDL More 
Detached or F2F Somewhat Supportive was characterized by lower frequency ratings across practices than the Highly Supportive profile and mostly lower ratings than the Instructor Centered — with a few exceptions, such as providing opportunities for collaborative work.

\section{Figure 3.}

Face-to-Face frequency of practices.

Highly Supportive (32\%)

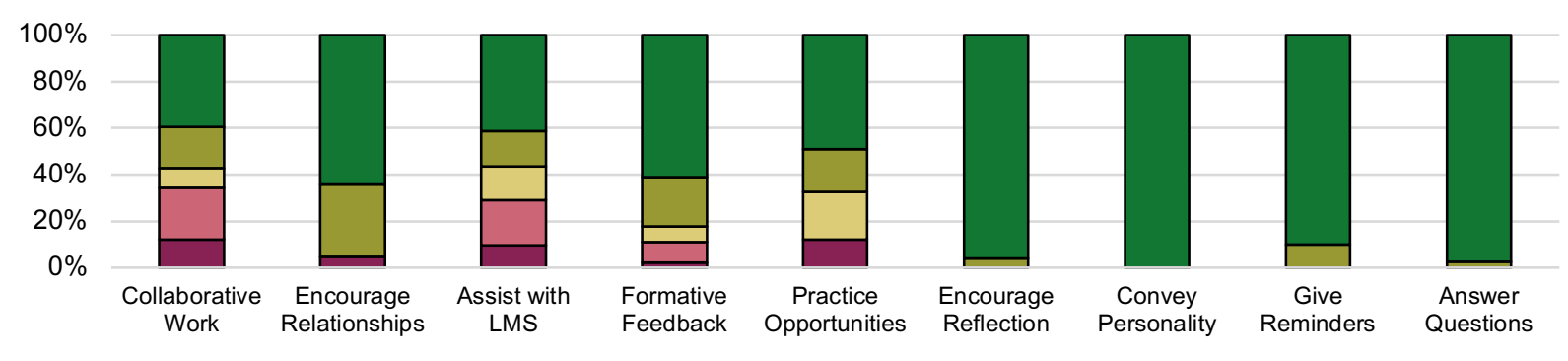

Instructor Centered (30\%)

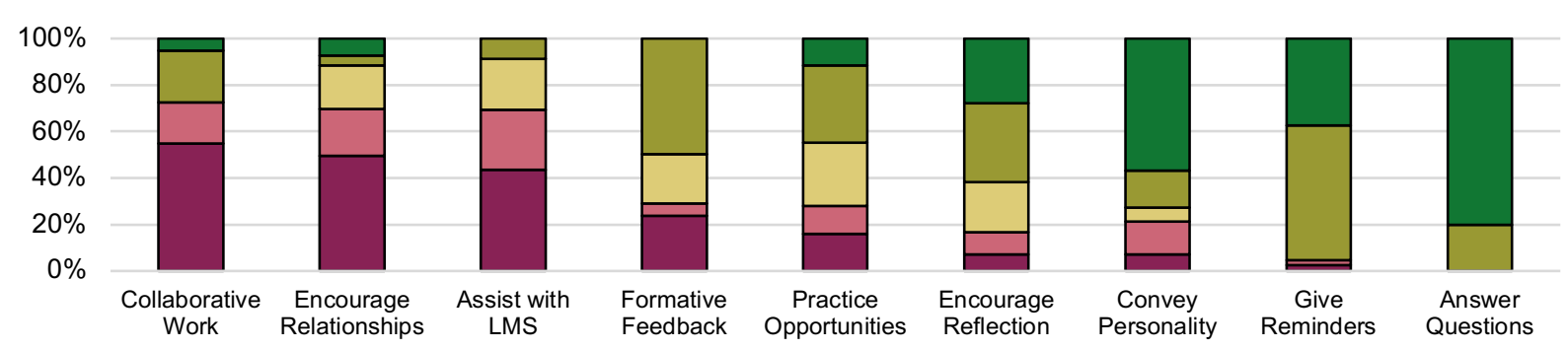

Somewhat Supportive (38\%)

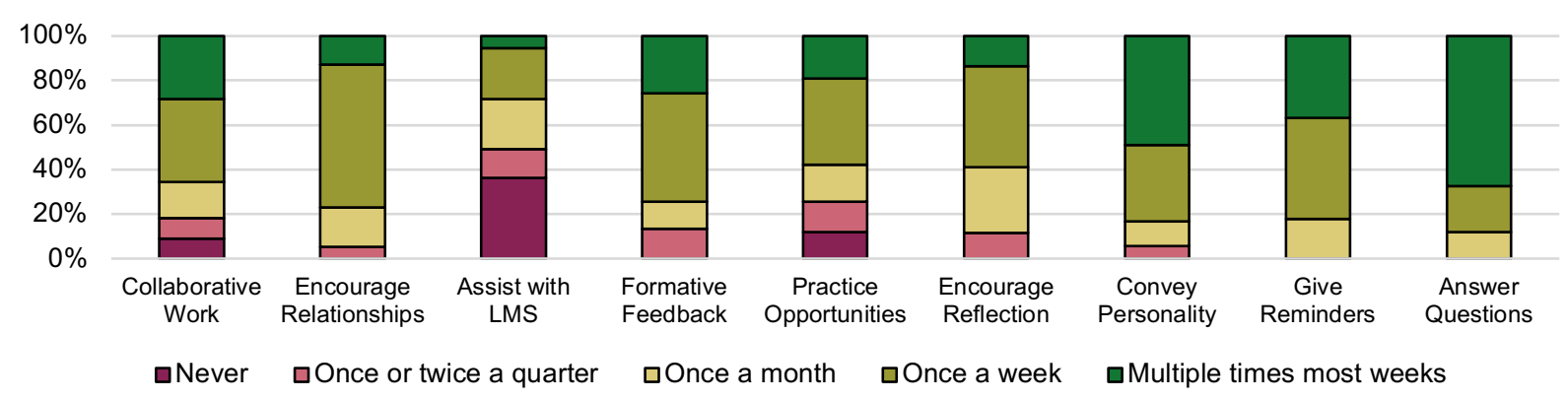

The F2F confidence profiles followed a similar pattern to the EDL confidence profiles, in that there was a high, medium, and low profile-Highly Confident (32\%), Moderately Confident (44\%), and Somewhat Confident (24\%; Figure 4). However, instructors reported higher confidence overall in F2F than EDL. Even instructors in the "lowest" F2F profile (Somewhat Confident) were more confident than the instructors in both the EDL Mid and Lower Confidence profiles. For example, in the F2F Somewhat Confident profile, approximately $30 \%$ of instructors noted they were at least "confident" in their ability to encourage relationships, whereas fewer than $10 \%$ of instructors in the EDL Mid and Lower Confidence profiles were at least "confident" in this practice. 


\section{Figure 4.}

Face-to-Face Confidence in practices.

Highly Confident (32\%)

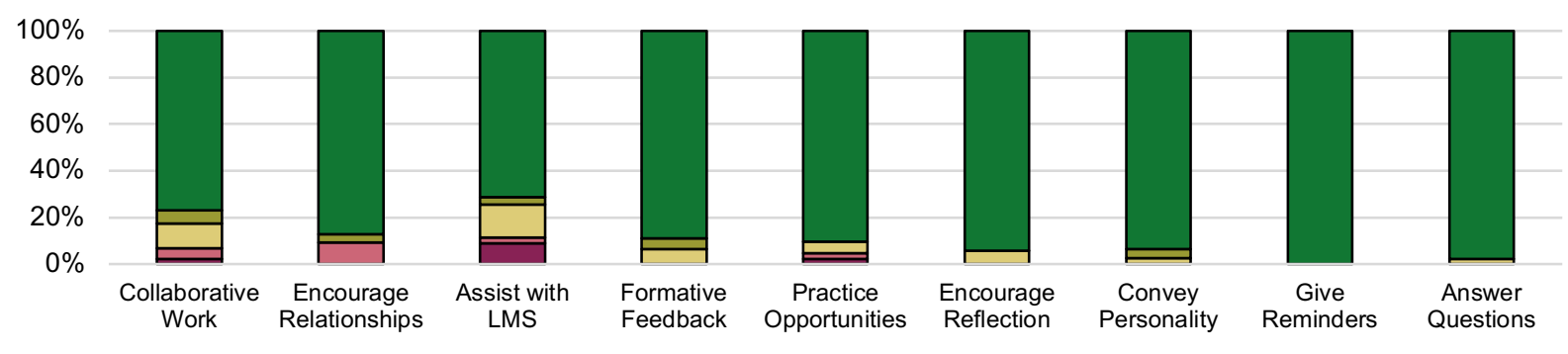

Moderately Confident (44\%)

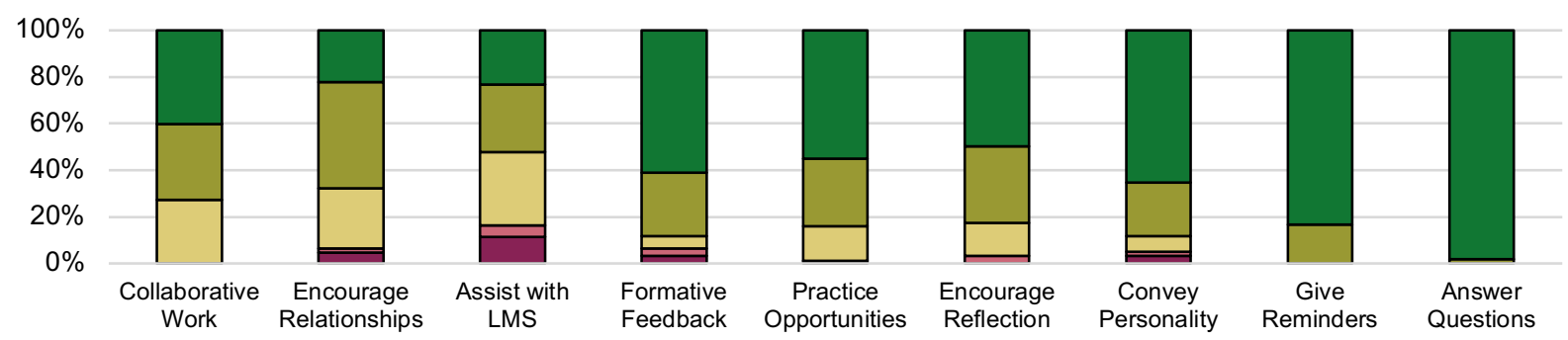

Somewhat Confident (24\%)

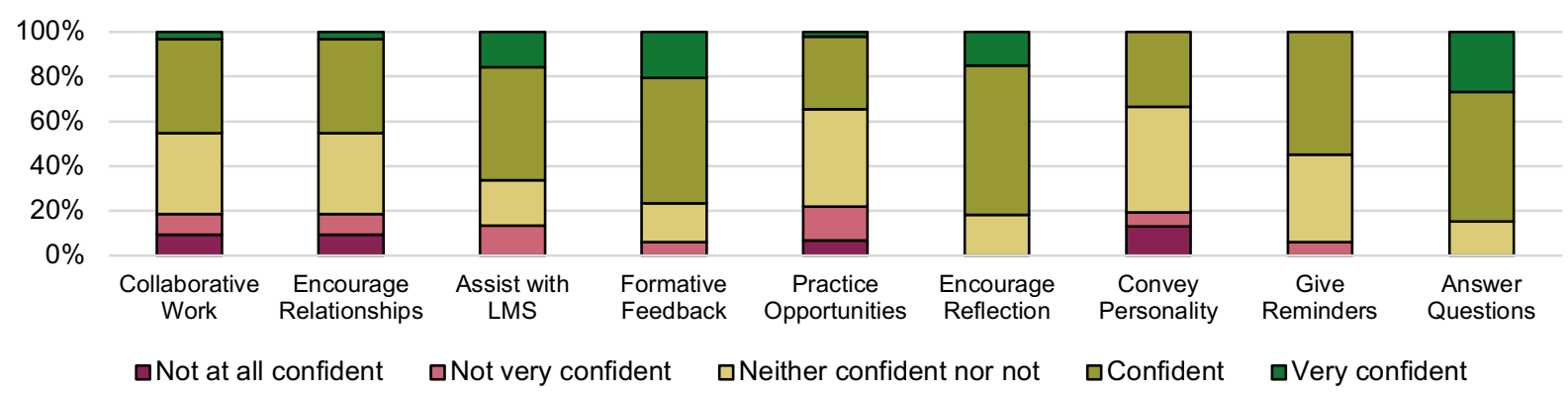

\section{Movement Between Profiles}

Two similar frequency profiles were found across both F2F and EDL contexts; additionally, the confidence profiles largely followed the same "high, medium, low" pattern. However, rarely did instructors stay in similar profiles between F2F and EDL contexts. In terms of frequencies of practice, instructors tended to shift "down" from a more-supportive to lesssupportive profile when moving from the F2F to EDL context (Table 3). In particular, among instructors in the F2F Highly Supportive profile, most shifted down to either the EDL Instructor Centered profile (34\%) or the EDL More Detached profile (30\%). Similarly, among faculty who were Instructor Centered in the F2F context, most shifted down to EDL More Detached (76\%), whereas very few shifted up to EDL Highly Supportive (7\%). Finally, among those who were Somewhat Supportive in F2F courses, over half remained in the bottom category of EDL More Detached (52\%). However, in contrast to the general trend of downshifting, about a third of F2F Somewhat Supportive did shift up to the EDL Highly Supportive profile (35\%), and a few shifted to Instructor Centered (13\%). 


\section{Table 3}

Movement from F2F to EDL Frequency Profiles

\begin{tabular}{lcccc} 
& \multicolumn{4}{c}{ EDL Profiles } \\
\cline { 2 - 5 } \multicolumn{1}{c}{ F2F Profiles } & Highly Supportive & Instructor Centered & More Detached & $N$ \\
\cline { 3 - 6 } Highly Supportive & $36 \%$ & $34 \%$ & $30 \%$ & 44 \\
Instructor Centered & $7 \%$ & $17 \%$ & $76 \%$ & 41 \\
Somewhat Supportive & $35 \%$ & $13 \%$ & $52 \%$ & 52 \\
$\mathrm{~N}$ & 37 & 29 & 71 & $\mathbf{1 3 7}$ \\
\hline
\end{tabular}

Instructors were more stable in their confidence (Table 4). Most instructors in the F2F Highly Confident profile remained in the highest confidence EDL profile (75\%, Higher Confidence). Instructors in the F2F Moderately Confident profile typically shifted "up" to the EDL Higher Confidence profile (47\%) or remained in the middle category (37\%). Instructors in the F2F lowestconfidence profile of Somewhat Confident tended to shift into EDL Mid Confidence (42\%) or remain in the lowest-confidence profile of EDL Lower Confidence (39\%).

\section{Table 4}

Movement from F2F to EDL Confidence Profiles

\begin{tabular}{lcccc}
\multirow{2}{*}{ F2F Profiles } & \multicolumn{4}{c}{ EDL Profiles } \\
\cline { 3 - 5 } & Higher Confidence & Mid Confidence & Lower Confidence & $N$ \\
Highly Confident & $75 \%$ & $16 \%$ & $9 \%$ & 44 \\
Moderately Confident & $47 \%$ & $37 \%$ & $17 \%$ & 60 \\
Somewhat Confident & $18 \%$ & $42 \%$ & $39 \%$ & 33 \\
$\mathrm{~N}$ & 67 & 43 & 27 & $\mathbf{1 3 7}$ \\
\hline
\end{tabular}

To examine the relations between profiles between and across contexts and question type (i.e., frequency and confidence), we also ran correlations between classification probabilities for each profile (Table 5). Recall that classification probabilities are continuous; for example, for F2F Confidence, an individual instructor could have a 75\% likelihood of being Highly Confident, a 25\% likelihood of being Moderately Confident, and a $0 \%$ likelihood of being Somewhat Confident, with summed likelihoods always equaling 100\% across the three profiles. In Table 5, correlations are generally in the expected direction; for example, an instructor with a high probability of being in the F2F Highly Confident profile has a higher probability of being in the F2F Highly Supportive profile and the EDL Higher Confidence profile; however, they do not necessarily have a higher probability of being in the EDL Highly Supportive profile. In Table 5, we are most interested in the correlates of instructor behaviors in the EDL context. Although correlations were typically quite mild, the patterns suggest the EDL Highly Supportive profile was more pronounced among instructors with strong Higher EDL Confidence, and with low F2F Instructor Centered and Somewhat Confident profile probabilities. The EDL More Detached profile probabilities were stronger among instructors who were in "lower" EDL and F2F confidence profiles, and who tended to be F2F Instructor Centered. 
Table 5

Correlations between Probabilities of Profile Membership

\begin{tabular}{|c|c|c|c|c|c|c|c|c|c|}
\hline \multirow[b]{2}{*}{ Variable } & \multicolumn{3}{|c|}{ F2F Frequency } & \multicolumn{3}{|c|}{ EDL Confidence } & \multicolumn{3}{|c|}{ EDL Frequency } \\
\hline & HS & IC & SS & $\mathrm{H}$ & $\mathrm{M}$ & L & HS & IC & $\mathrm{MD}$ \\
\hline $\begin{array}{l}\text { O Highly } \\
\text { E Confident }\end{array}$ & $.43^{\mathrm{c}}$ & $-.17^{\mathrm{a}}$ & $-.27^{b}$ & $.38^{\mathrm{c}}$ & $-.26^{\mathrm{b}}$ & $-.18^{\mathrm{a}}$ & .04 & $.19^{\mathrm{a}}$ & $-.19^{\mathrm{a}}$ \\
\hline $\begin{array}{l}\text { Moderately } \\
\text { ¿ Confident }\end{array}$ & -.14 & .02 & .13 & -.01 & .10 & -.09 & .12 & -.17 & .03 \\
\hline $\begin{array}{l}\text { I Somewhat } \\
\text { I Confident }\end{array}$ & $-.30^{c}$ & .17 & .14 & $-.39^{c}$ & .16 & $.30^{\mathrm{c}}$ & $-.18^{\mathrm{a}}$ & -.02 & .17 \\
\hline $\begin{array}{l}\text { Highly } \\
\text { Uू Supportive }\end{array}$ & & & & $.29^{\mathrm{c}}$ & $-.22^{\mathrm{b}}$ & -.11 & .12 & $.27^{\mathrm{b}}$ & $-.33^{c}$ \\
\hline $\begin{array}{l}\text { 总 Instructor } \\
\text { 产 Centered }\end{array}$ & & & & -.09 & .07 & .04 & $-.27^{b}$ & -.10 & $.32^{\mathrm{c}}$ \\
\hline $\begin{array}{l}\text { Somewhat } \\
\text { 工工 Supportive }\end{array}$ & & & & $-.20^{\mathrm{a}}$ & .16 & .07 & .14 & $-.17^{\mathrm{a}}$ & .02 \\
\hline $\begin{array}{l}\text { Higher } \\
\text { Confidence }\end{array}$ & & & & & & & $.19^{\mathrm{a}}$ & $.19^{\mathrm{a}}$ & $-.32^{\mathrm{c}}$ \\
\hline 空 $\begin{array}{l}\mathrm{Mid} \\
\text { Confidence }\end{array}$ & & & & & & & -.13 & -.10 & $.19^{\mathrm{a}}$ \\
\hline $\begin{array}{l}\text { Lower } \\
\text { Confidence }\end{array}$ & & & & & & & -.09 & -.12 & $.18^{\mathrm{a}}$ \\
\hline
\end{tabular}

Note. ${ }^{\mathrm{a}} p<.05,{ }^{\mathrm{b}} p<.01,{ }^{\mathrm{c}} p<.001$

\section{Regressions-Question 2: What predicts membership in EDL frequency profiles?}

\section{Hierarchical Regressions}

Table 6 shows the results of three different models performed for three different outcomes - the membership probabilities for each of the three EDL Frequency profiles - for a total of nine models. For each model, the table displays the beta weight for each predictor, with the omitted profile in each set (F2F Highly Supportive or EDL Higher Confidence) serving as the reference for the remaining two. The first model ("M1") included only instructor background characteristics, which did not explain a statistically significant amount of variance in profile membership probability ( $\mathrm{R}^{2}$ 's ranging from $3 \%$ to $7 \%$, $p$ 's ranging from .159 to .570 ).

Adding the F2F frequency profiles as predictors ("M2") statistically significantly improved the amount of variance explained for all EDL frequency profiles (increase in $\mathrm{R}^{2}$ ranging from $5 \%$ to $12 \%, p$ 's $<.05$ ). Finally, adding the EDL confidence profiles as predictors ("M3") statistically significantly improved the variance explained for only the EDL More Detached outcome (increase in $\left.\mathrm{R}^{2}=7 \%, p=.005\right)$. Accordingly, in the model interpretation below, we rely on Model 2 for EDL Highly Supportive $\left(\mathrm{R}^{2}=11 \%, p=.048\right)$ and EDL Instructor Centered $\left(\mathrm{R}^{2}=10 \%, p=.085\right)$, but Model 3 for EDL More Detached $\left(\mathrm{R}^{2}=22 \%, p<.001\right)$. 


\section{Table 6}

Hierarchical Regression of EDL Frequency Profile Membership Probability on Instructor Background Characteristics and Profiles

\begin{tabular}{|c|c|c|c|c|c|c|c|c|c|}
\hline \multirow[b]{2}{*}{ Variable } & \multicolumn{3}{|c|}{$\begin{array}{l}\text { EDL Highly } \\
\text { Supportive }\end{array}$} & \multicolumn{3}{|c|}{$\begin{array}{c}\text { EDL Instructor } \\
\text { Centered }\end{array}$} & \multicolumn{3}{|c|}{ EDL More Detached } \\
\hline & M1 & M2 & M3 & M1 & M2 & M3 & M1 & M2 & M3 \\
\hline \multicolumn{10}{|l|}{ Background } \\
\hline DL Experience & $<-0.01$ & $<-0.01$ & -0.02 & 0.08 & 0.07 & 0.05 & -0.06 & -0.05 & -0.02 \\
\hline STEM & 0.05 & 0.02 & 0.05 & 0.11 & 0.10 & 0.12 & -0.13 & -0.10 & -0.14 \\
\hline Family Care & 0.04 & 0.02 & 0.01 & 0.03 & 0.01 & $<0.01$ & -0.06 & -0.02 & -0.01 \\
\hline Whether a Man & -0.14 & -0.10 & -0.09 & -0.03 & -0.03 & -0.02 & 0.15 & 0.12 & 0.09 \\
\hline TT Teaching & 0.17 & 0.13 & 0.15 & -0.17 & -0.17 & -0.15 & -0.01 & 0.02 & $<-0.01$ \\
\hline Lecturer & 0.18 & 0.12 & 0.12 & -0.10 & -0.18 & -0.18 & -0.08 & 0.05 & 0.04 \\
\hline \multicolumn{10}{|l|}{ F2F Frequency } \\
\hline Inst. Centered & & $-0.23^{a}$ & -0.20 & & $-0.26^{a}$ & $-0.23^{a}$ & & $0.42^{c}$ & $0.36^{c}$ \\
\hline Some Support & & -0.02 & 0.03 & & $-0.28^{b}$ & $-0.25^{a}$ & & $0.25^{\mathrm{a}}$ & 0.18 \\
\hline \multicolumn{10}{|l|}{ EDL Confidence } \\
\hline Mid & & & -0.16 & & & -0.12 & & & $0.24^{b}$ \\
\hline Lower & & & -0.15 & & & -0.14 & & & $0.25^{b}$ \\
\hline $\mathbf{R}^{2}$ & 0.07 & $0.11^{a}$ & $0.14^{a}$ & 0.03 & 0.10 & 0.12 & 0.04 & $0.16^{b}$ & $0.22^{c}$ \\
\hline adjusted $R^{2}$ & 0.03 & 0.06 & 0.07 & -0.01 & 0.04 & 0.05 & $<0.01$ & 0.10 & 0.16 \\
\hline$\Delta R^{2}$ & & $0.05^{a}$ & 0.03 & & $0.07^{a}$ & 0.02 & & $0.12^{c}$ & $0.07^{b}$ \\
\hline
\end{tabular}

Note. Reference groups = Tenure Track Research Faculty, F2F Highly Supportive Profile,

EDL Higher Confidence Profile

F2F $=$ Face-to-Face; EDL $=$ Emergency Distance Learning

${ }^{\mathrm{a}} p<.05,{ }^{\mathrm{b}} p<.01,{ }^{\mathrm{c}} p<.001$; significant values are bolded

$\mathrm{N}=137$

In terms of the EDL Highly Supportive profile, the only statistically significant finding echoed the bivariate correlation results: those beginning in the F2F Instructor Centered profile were less likely to end up in this profile $(\beta=-0.23, p=.03)$. In terms of the EDL Instructor Centered profile, those beginning in the F2F Instructor Centered and Somewhat Supportive profiles were less likely to end up in this profile $(\beta=-0.263, p=.013 ; \beta=-0.284, p=.006$, respectively), which in turn indicates that instructors beginning in the Highly Supportive F2F profile were most likely to end up in the EDL Instructor Centered profile. Finally, in terms of the EDL Detached profile, instructors who began in the F2F Instructor Centered profile were more likely to end up in this profile $(\beta=0.36, p<.001)$. EDL confidence was also predictive of membership in EDL More Detached - on average, instructors in the EDL Mid Confidence and Lower Confidence profiles were more likely to be in the EDL More Detached profile $(\beta=0.24, p=.008 ; \beta=0.25, p=.006$, respectively). To illustrate the key results from the regression models, Figure 5 shows the modelbased predicted probabilities of ending up in each EDL Frequency profile, based on one's categorical classification in terms of the F2F Frequency and EDL Confidence profiles. 


\section{Figure 5.}

Predicted probability of EDL frequency profile membership by $F 2 F$ frequency and $E D L$ confidence profiles

\section{By F2F Frequency Profiles}
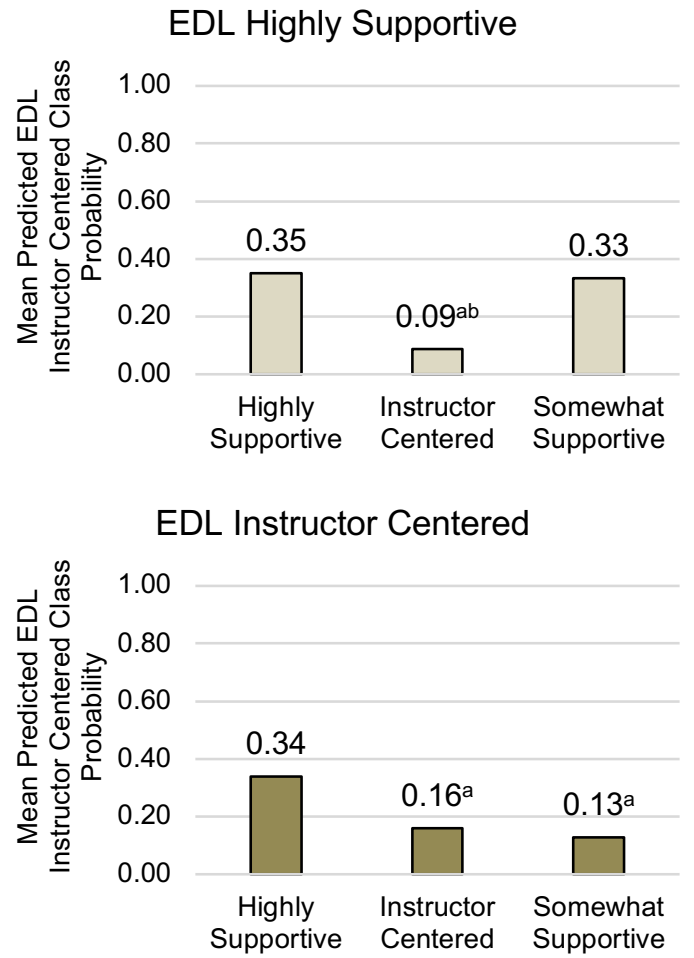

EDL More Detached

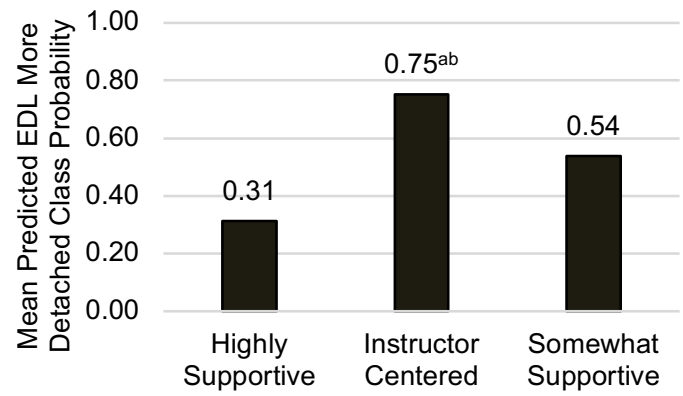

By EDL Confidence Profiles*

not statistically significant

not statistically significant

EDL More Detached

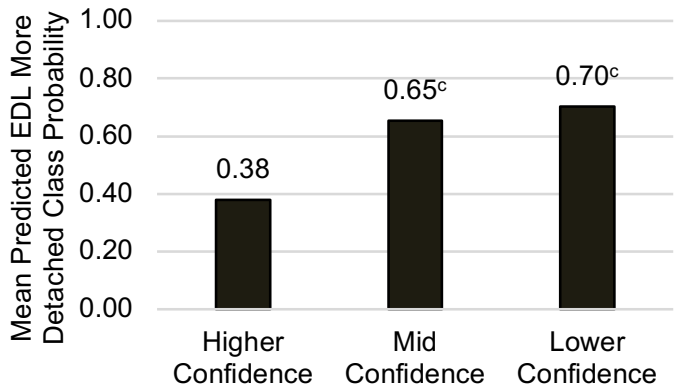

Note. EDL Highly Supportive and Instructor Centered predicted values and post-hoc comparisons are from Step Two of the hierarchical regression; EDL More Detached predicted values and post-hoc comparisons are from Step Three.

*EDL Highly Supportive and Instructor Centered did not have comparisons by EDL confidence profiles because results from Step Two are used (there was no significant difference in $\mathrm{R}^{2}$ by adding EDL confidence profiles in Step Three).

a Statistically significantly different from F2F Highly Supportive

${ }^{\mathrm{b}}$ Statistically significantly different from F2F Somewhat Supportive

c Statistically Significantly different from EDL Higher Confidence 
Statistically significant differences between predictor profiles were determined via the regression model or post-hoc comparisons. For example, when instructors were in the F2F Highly Supportive profile, they had a 35\% probability of being in the EDL Highly Supportive profile, after accounting for instructor background characteristics. This probability of being in the EDL Highly Supportive profile did not statistically significantly differ when the instructor was in the F2F Somewhat Supportive profile (0.33) as compared to the F2F Highly Supportive profile (0.35). However, instructors were statistically significantly less likely to be in the EDL Highly Supportive profile if they were in the F2F Instructor Centered profile (0.09), compared to both the F2F Highly and Somewhat Supportive profiles.

\section{Regressions with F2F Practices}

In order to understand how instructors' specific behaviors in the F2F context predicted their EDL behaviors, we regressed EDL frequency profile membership probabilities on instructor background characteristics and individual F2F practice frequencies; Table 7 shows the beta coefficients for each predictor of each outcome. Together, these variables did not explain a statistically significant amount of variance in the EDL Instructor Centered membership probability $\left(\mathrm{R}^{2}=14 \%, p=.210\right)$, but did explain a statistically significant amount of variance in the EDL Highly Supportive $\left(\mathrm{R}^{2}=26 \%, p=.001\right)$ and More Detached $\left(\mathrm{R}^{2}=21 \%, p=.013\right)$ profiles.

Instructors who, on average, gave formative feedback and practice opportunities more frequently in their face-to-face course(s) were more likely to be in the Highly Supportive profile during emergency distance learning $(\beta=0.248, p=.008 ; \beta=0.047, p=.006$, respectively). This aligns with the profile regressions above, as these two practices were among those that distinguished the F2F Instructor Centered and Highly Supportive profiles. Formative feedback in particular was reported at the lowest frequency in the F2F Instructor Centered profile relative to the other two profiles. In considering what predicted the EDL More Detached profile, assistance with the LMS emerged as the only statistically significant predictor-instructors who, on average, did not frequently help their students with the LMS in their face-to-face course(s) were more likely to be in the More Detached profile during emergency distance learning $(\beta=-0.272, p=.006)$. This also is consistent with profile results, as those in the F2F Highly Supportive profile reported the largest prevalence of helping their students with the LMS. See Table 7 for full model results. 


\section{Table 7}

Regression of EDL Frequency Profile Membership Probability on Instructor Background Characteristics and F2F Practices

\begin{tabular}{lccc}
\hline Variable & $\begin{array}{c}\text { EDL Highly } \\
\text { Supportive }\end{array}$ & $\begin{array}{c}\text { EDL Instructor } \\
\text { Centered }\end{array}$ & $\begin{array}{c}\text { EDL More } \\
\text { Detached }\end{array}$ \\
\hline Instructor Background & & & \\
DL Experience & 0.008 & -0.004 & -0.004 \\
STEM & -0.064 & 0.136 & -0.057 \\
Family Care & -0.015 & 0.048 & -0.027 \\
Whether a Man & -0.138 & 0.002 & 0.119 \\
TT Teaching & 0.070 & -0.128 & 0.045 \\
Lecturer & -0.034 & -0.105 & 0.117 \\
\hline F2F Frequency of Practices & & & \\
Collaborative Work & 0.089 & -0.065 & -0.024 \\
Encourage Relationships & 0.005 & 0.088 & -0.077 \\
Assist with LMS & 0.180 & 0.138 & $\mathbf{- 0 . 2 7 2}$ \\
Formative Feedback & $\mathbf{0 . 2 4 8}$ & -0.082 & -0.148 \\
Practice Opportunities & $\mathbf{0 . 1 9 1}$ & -0.109 & -0.076 \\
Encourage Reflection & 0.131 & 0.008 & -0.121 \\
Convey Personality & -0.140 & 0.137 & -0.008 \\
Give Reminders & -0.159 & 0.130 & 0.031 \\
Answer Questions & 0.019 & 0.027 & -0.039 \\
\hline R $^{\mathbf{2}}$ & $\mathbf{0 . 2 5 6}^{\mathbf{b}}$ & 0.139 & $\mathbf{0 . 2 0 8}$ \\
(adjusted R ${ }^{\mathbf{a}}$ ) & $(0.164)$ & $(0.033)$ & $(0.110)$ \\
\hline Note. Tenure Track Rescarch Faculty & & \\
\hline
\end{tabular}

Note. Tenure Track Research Faculty used as reference group.

$\mathrm{F} 2 \mathrm{~F}=$ Face-to-Face; EDL $=$ Emergency Distance Learning

${ }^{\mathrm{a}} p<.05,{ }^{\mathrm{b}} p<.01,{ }^{\mathrm{c}} p<.001$; statistically significant values are bolded

$\mathrm{N}=137$

\section{Discussion}

Within this study we examined how university instructors facing EDL reported teaching their courses in both an EDL format and a previously-taught F2F format. Instructors reported the frequency with which they engaged in nine practices focusing on interactions between instructors and students, students and peers, and students and the course content. Using LCA, three profiles of interaction-oriented practice frequency emerged in each context. Both EDL and F2F contexts contained a Highly Supportive profile, characterized by high reported frequency of all practices. Both contexts also contained a more Instructor-Centered profile, characterized by high frequency of instructor-student interactions, such as conveying personality and providing reminders, but lower frequency of student-peer interactions, such as collaborative work and encouraging relationships. Instructor-centered profiles also reported lower frequency of supporting interactions between students and the course content, especially with regard to assisting with the LMS. Instructors in this profile also reported lower frequency of providing formative feedback, which, although this can be seen as an instructor-student interaction, may also be seen as facilitating 
students' deeper engagement with the course content through supporting self-regulation (Nicol \& Macfarlane-Dick, 2006). The third profile in each of the contexts differed with respect to reported frequency: within the F2F context, instructors in the Somewhat Supportive profile reported a similar frequency pattern to those in the Highly Supportive profile, but at slightly lower levels, with few practices being reported as "never" or only "once or twice a quarter." In contrast, the third EDL profile-More Detached - had lower frequency of all reported practices, including over $25 \%$ and for some practices over $50 \%$, reported as occurring "never" or "once or twice a quarter." The similarity of the profiles that emerged across F2F and EDL contexts provide support for the notion that examination of practices focusing on interactions is one that can apply between contexts. Although we used a different measure, the demarcation between instructor-centered and highly supportive instructors is in line with the differentiation between didactic and more interactive or student-centered profiles found by Stains et al. (2018). Unlike Stains et al. (2018), the majority of instructors in our study were not in the instructor-centered profile, even in the F2F context (30\% in our study, compared to $55 \%$ in Stains et al.). In addition to the specific measure differences, instructors in our study retrospectively reported on practices in F2F instances of their course. It may be that in comparison to their EDL practices, they inflated the interactive nature of their F2F instruction.

The lack of stability between instructor profile membership across contexts is in line with research noting the differences between F2F and online instruction (e.g., Cavanaugh, 2005; Horvitz et al., 2015). The instructors in our study rarely were in the same profile in both F2F and EDL settings, and often shifted "down" from a more-supportive to less-supportive profile when they moved from the F2F to EDL setting. As one interesting movement group, those who were in the F2F Instructor Centered profile were most likely to move to the EDL More Detached profile despite the availability of the EDL Instructor Centered profile, characterized by a very similar pattern of reported frequencies across practices. One possible explanation for this is that those in the F2F Instructor Centered profile had competencies around instructor-student interactions that did not translate to the online context of EDL, or the demands of moving to a new modality and coping with the pandemic left instructors with insufficient bandwidth to translate them. Another possible explanation is that instructors whose teaching was dominated with instructor-student interactions in F2F contexts did not engage in these interactions with the same frequency in EDL because they did not enjoy interacting with students within the constraints of the online context. ${ }^{1}$ There are other competing explanations for this movement between profiles. Our retrospective reporting format could have resulted in a systematic bias that applied differently to different modalities (for instance, pre-March life has a rosy hue in June). Low instructor confidence may also have facilitated a shift between profiles, given that instructors with mid or lower EDL confidence were more likely to end up in the EDL More Detached profile.

In general, we might expect instructors who began in the F2F Highly Supportive profile to stay in the EDL Highly Supportive profile, and indeed they did (compared to their peers who began in the F2F Instructor Centered group); however, they were also the most likely to end up in the EDL Instructor Centered profile. The first result is consistent with an idea that highly supportive instructors engage in supportive practices regardless of the context; the second result is more difficult to explain. In the face-to-face context, Highly Supportive instructors reported that they

\footnotetext{
${ }^{1}$ At the end of our surveys, we provided instructors an opportunity for free response. A number of instructors commented on this aspect of the online format; one representative comment noted that teaching online, "remove[d] the joy of teaching: connection to students."
} 
frequently facilitated collaborative work and encouraged relationships, yet after the switch to EDL, those from this group who ended up in EDL Instructor Centered largely reported they "never" or "only once or twice a quarter" engaged in these practices. There are two potential explanations for the stronger likelihood of highly-supportive F2F instructors to end up in the Instructor Centered EDL profile. First, switching from F2F to online learning is challenging and involves different structures and skills than those used in F2F instruction (Kebritchi et al., 2017). This difference may be especially true for elements that involve student-peer interactions, as facilitating online classroom communities is particularly challenging (Means et al., 2014). Although we measured confidence with practices and online experience, it may be that confidence and skill with technology or technological pedagogy (see Benson et al., 2013) can explain this shift. Second, perhaps F2F highly supportive instructors purposefully reduced collaboration and peer work to accommodate the specific situation of EDL during the pandemic. In a survey of faculty during the early weeks of the pandemic, Johnson et al. (2020) found that faculty expressed care and concern for students by attempting to accommodate their needs through instructional decisions. Moving to more flexible (e.g., asynchronous) learning structures may meet some student needs, but would likely reduce opportunity for collaborative work and relationship building. This does not explain the lack of engagement with student formative feedback and reflection among those in the EDL Instructor Centered profile, however.

Unlike the frequency profiles, confidence profiles were not characterized by qualitatively different ratings across practices. Instead, a relatively high, mid, and low profile emerged in both contexts. Overall, mean levels of confidence in each EDL confidence profile were lower than those in the corresponding F2F profiles. Supporting the view that fostering student-peer relationships is perceived as difficult in the online environment, in each EDL confidence profile, instructors rated themselves as least confident in engaging in practices around collaborative learning and encouraging relationships. In the F2F confidence profiles, assisting with the LMS had the lowest confidence ratings across profiles.

Turning to instructor background characteristics, prior research has shown a number of background factors, such as type of teaching experience, predict both instructor practices and selfefficacy (e.g., Henderson et al., 2012; Horvitz et al., 2015; Walter et al., 2017). However, none of our instructor characteristic variables were predictive of any of the EDL profiles. It may be that in the EDL context, experience teaching online is less predictive of high-quality practices.

\section{Limitations}

Although our survey was distributed to every instructor that met our criteria, and the sample was relatively representative of the population in terms of readily observable characteristics, our response rate of $37 \%$ leaves open the possibility that our sample suffered from selection effects. That we were only able to gather detailed information on respondents - and had scant personal information-makes it difficult to ascertain how our respondents compared to the target survey population. Similarly, our generalizability may be limited to similar institutions (large, research-focused universities that have both teaching and research tenure-line faculty). Replication across additional samples and universities can lend further support for our results.

We are also limited in our insight as to what exactly was happening in our instructors' courses. Instructors may have varied in their use of synchronous and asynchronous methods, as well as aspects of the LMS or additional tools to support online learning. It may be that different methods of online instruction lend themselves to different interaction-oriented practices. Future 
research should examine how specific online learning context influences instruction profiles, such as ours.

\section{Implications for Practice}

We found that during the emergency shift to online instruction due to the COVID-19 pandemic, instructors tended to shift from highly-supportive F2F profiles to less supportive EDL profiles, which emphasizes the need for universities to support instructors transitioning to online learning. Prior research on online instruction has noted the need for instructors to have models of high-quality online instruction (Kebritchi et al., 2017) and to have clear institutional guidelines for what is expected in online courses (Anderson et al., 2011). During emergency situations such as the pandemic, these models and guidelines may even - and maybe especially — be important for instructors who engage in high-quality F2F instruction. We had no evidence as to whether instructors at our university had these supports; the lack of relation between online teaching experience and our highly-supportive EDL profile indicates they may not have. Unique to EDL, as instructors attempt to balance the needs of their students (see Johnson et al., 2020) they may make decisions to prioritize flexibility and student access at the expense of student-peer interactions. Although flexibility is likely key during EDL, the isolation normally experienced with online courses (McInnerney \& Roberts, 2004) may be increased during the pandemic (Elmer, 2020); universities can assist instructors in engaging in practices that increase student-peer interaction in a way consistent with flexibility and access.

After the shift to EDL, the largest number of instructors in our sample were classified as belonging to the More Detached profile. Although this profile was characterized with relatively few frequent promising practices, even instructors labeled as More Detached interacted with students by sending reminders and answering questions. Universities and students can take heart that no profiles emerged wherein instructors reported they "never" engaged in interactive practices across the board. This is in line with the good intentions found by Johnson et al. (2020). Still, this More Detached profile presents few opportunities for student-peer or student-content interactions. As lower levels of EDL confidence were predictive of this profile membership, universities can support instructors by building confidence for these practices in online contexts. Practice opportunities, successful peer models, and guidelines that explain the importance of practices for student learning can help to build confidence in online instruction (Horvitz et al., 2015; Martin et al., 2019) and move instructors toward more supportive profiles of practices.

\section{Disclaimer}

This material is based upon work supported by the National Science Foundation under Grant Nos. 1535300, 1750386, DUE 1821724, and DGE 1746939. 


\section{References}

Alpay, E., \& Verschoor, R. (2014). The teaching researcher: Faculty attitudes towards the teaching and research roles. European Journal of Engineering Education, 39(4), 365376.

Anderson, D., Imdieke, S., \& Standerford, N. S. (2011). Feedback please: Studying self in the online classroom. International Journal of Instruction, 4(1), 3-15.

Andrews, T. C., \& Lemons, P. P. (2015). It's personal: Biology instructors prioritize personal evidence over empirical evidence in teaching decisions. CBE-Life Sciences Education, 14(1), ar7. https://doi.org/10.1187/cbe.14-05-0084

Avery, M. D., Cohen, B. A., \& Walker, J. D. (2008). Evaluation of an online graduate nursing curriculum: Examining standards of quality. International Journal of Nursing Education Scholarship, 5(1).

Bandura, A. (1997). Self-efficacy: The exercise of control. Freeman.

Benson, S. N. K., \& Ward, C. L. (2013). Teaching with technology: Using TPACK to understand teaching expertise in online higher education. Journal of Educational Computing Research, 48(2), 153-172.

Broadbent, J., \& Poon, W. L. (2015). Self-regulated learning strategies \& academic achievement in online higher education learning environments: A systematic review. The Internet and Higher Education, 27, 1-13.

Burić, I., \& Moe, A. (2020). What makes teachers enthusiastic: The interplay of positive affect, self-efficacy and job satisfaction. Teaching and Teacher Education, 89, Article 103008.

Cadez, S., Dimovski, V., \& Groff, M. Z. (2017). Research, teaching and performance evaluation in academia: the salience of quality." Studies in Higher Education, 42(8), 1455-1473.

Cavanaugh, J. (2005). Teaching online: A time comparison. Online Journal of Distance Learning Administration, 8(1).

Chang, T. S., Lin, H. H., \& Song, M. M. (2011). University faculty members' perceptions of their teaching efficacy. Innovations in Education and Teaching International, 48(1), 4960 .

Chestnut, S. R., \& Burley, H. (2015). Self-efficacy as a predictor of commitment to the teaching profession: A meta-analysis. Educational Research Review, 15, 1-16.

Collins, L. M. (2001). Reliability for static and dynamic categorical latent variables: Developing measurement instruments based on a model of the growth process. In L. Collins \& A. Sayer (Eds.), New methods for the analysis of change (pp. 271-288). American Psychological Association.

Collins, L. M., \& Lanza, S. T. (2010). Latent class and latent transition analysis: With applications in the social, behavioral, and health sciences. Wiley.

Delen, E., \& Liew, J. (2016). The use of interactive environments to promote self-regulation in online learning: A literature review. European Journal of Contemporary Education, 15(1), 24-33. 
Deslauriers, L., Schelew, E., \& Wieman, C. (2011). Improved learning in a large-enrollment physics class. Science, 332(6031), 862-864.

Deslauriers, L., McCarty, L. S., Miller, K., Callaghan, K., \& Kestin, G. (2019). Measuring actual learning versus feeling of learning in response to being actively engaged in the classroom. Proceedings of the National Academy of Sciences, 116(39), 19251-19257. https://doi.org/10.1073/pnas.1821936116

Eddy, S. L., and Hogan, K. A. (2014). Getting under the hood: how and for whom does increasing course structure work? CBE-Life Sciences Education, 13(3), 453-468.

Ebert-May, D., Derting, T. L., Hodder, J., Momsen, J. L., Long, T. M., \& Jardeleza, S. E. (2011). What we say is not what we do: Effective evaluation of faculty professional development programs. BioScience, 61(7), 550-558. https://doi.org/10.1525/bio.2011.61.7.9

Elmer, T., Mepham, K., \& Stadtfeld, C. (2020). Students under lockdown: Comparisons of students' social networks and mental health before and during the COVID-19 crisis in Switzerland. Plos One, 15(7), Article e0236337.

Fischer, C., Xu, D., Rodriguez, F., Denaro, K., \& Warschauer, M. (2020). Effects of course modality in summer session: Enrollment patterns and student performance in face-to-face and online classes. The Internet and Higher Education, 45, Article 100710.

Freeman, S., Eddy, S. L., McDonough, M., Smith, M. K., Okoroafor, N., Jordt, H., Wenderoth, M. P. (2014). Active learning increases student performance in science, engineering, and mathematics. Proceedings of the National Academy of Sciences, 111(23), 8410-8415.

Freeman,S., Haak, D., \& Wenderoth, M.P. (2011). Increased course structure improves performance in introductory biology. CBE Life Science Education, 10(2), 175-186.

Freeman, S., O’Connor, E., Parks, J.W., Cunningham, M., Hurley, D., Haak, D., Dirks, C., \& Wenderoth, M.P. (2007). Prescribed active learning increases performance in introductory biology. CBE-Life Sciences Education, 6(2), 132-139.

Grandzol, C. J., \& Grandzol, J. R. (2010). Interaction in online courses: More is not always better. Online Journal of Distance Learning Administration, 13(2).

Haak, D., HilleRisLambers, J., Pitre, M., \& Freeman, S. (2011). Increased structure and active learning reduce the achievement gap in introductory biology. Science, 332(6034), 12131216

Hagenaars, J. A., \& McCutcheon, A. L. (Eds.). (2002). Applied latent class analysis. Cambridge University Press.

Henderson, C., Beach, A., \& Finkelstein, N. (2011). Facilitating change in undergraduate STEM instructional practices: An analytic review of the literature. Journal of Research in Science Teaching, 48(8), 952-984. https://doi.org/10.1002/tea.20439

Henderson, C., \& Dancy, M. H. (2007). Barriers to the use of research-based instructional strategies: The influence of both individual and situational characteristics. Physical Review Special Topics—Physics Education Research, 3(2), Article 020102. https://doi.org/10.1103/PhysRevSTPER.3.020102 
Henderson, C., Dancy, M., \& Niewiadomska-Bugaj, M. (2012). Use of research-based instructional strategies in introductory physics: Where do faculty leave the innovationdecision process? Physical Review Special Topics-Physics Education Research, 8(2), Article 020104. https://doi.org/10.1103/PhysRevSTPER.8.020104

Horvitz, B. S., Beach, A. L., Anderson, M. L., \& Xia, J. (2015). Examination of faculty selfefficacy related to online teaching. Innovative Higher Education, 40(4), 305-316.

Hutti, D. L. (2007). Online learning, quality, and Illinois community colleges. MERLOT Journal of Online Learning and Teaching, 3(1).

Jaggars, S. S., \& Xu, D. (2016). How do online course design features influence student performance? Computers \& Education, 95, 270-284.

Johnson, G., \& Davies, S. (2014). Self-regulated learning in digital environments: Theory, research, praxis. British Journal of Research, 1(2), 1-14.

Johnson, N., Veletsianos, G., \& Seaman, J. (2020). U.S. faculty and administrators' experiences and approaches in the early weeks of the COVID-19 pandemic. Online Learning, 24(2), 6-21.

Kear, K., Chetwynd, F., \& Jefferis, H. (2014). Social presence in online learning communities: The role of personal profiles. Research in Learning Technology, 22.

Kebritchi, M., Lipschuetz, A., \& Santiague, L. (2017). Issues and challenges for teaching successful online courses in higher education: A literature review. Journal of Educational Technology Systems, 46(1), 4-29.

Keeton, M. T. (2004). Best online instructional practices: Report of phase I of an ongoing study. Journal of Asynchronous Learning Networks, 8(2), 75-100.

Kitsantas, A., \& Dabbagh, N. (2004). Supporting self-regulation in distributed learning environments with web-based pedagogical tools: An exploratory study. Journal on Excellence in College Teaching, 15(1), 119-142.

Martin, F., \& Bolliger, D. U. (2018). Engagement matters: Student perceptions on the importance of engagement strategies in the online learning environment. Online Learning, 22(1), 205-222.

Martin, F., Wang, C., Jokiaho, A., May, B., \& Grübmeyer, S. (2019). Examining faculty readiness to teach online: A comparison of U.S. and German educators. European Journal of Open, Distance and E-learning, 22(1), 53-69.

McDaniel, M. A., Wildman, K. M., \& Anderson, J. L. (2012). Using quizzes to enhance summative-assessment performance in a web-based class: An experimental study. Journal of Applied Research in Memory and Cognition, 1(1), 18-26.

McDavid, L., Parker, L. C., Burgess, W., Robertshaw, B., \& Doan, T. (2018). The combined effect of learning space and faculty self-efficacy to use student-centered practices on teaching experiences and student engagement. Journal of Learning Spaces, 7(1), 29-44.

McInnerney, J. M., \& Roberts, T. S. (2004). Online learning: Social interaction and the creation of a sense of community. Journal of Educational Technology \& Society, 7(3), 73-81. 
Means, B., Bakia, M., \& Murphy, R. (2014). Learning online: What research tells us about whether, when and how. Routledge.

Michael, J. (2007). Faculty perceptions about barriers to active learning. College Teaching, 55(2), 42-47. https://doi.org/10.3200/CTCH.55.2.42-47

Moore, J. (2005). Seven recommendations for creating sustainability education at the university level. International Journal of Sustainability in Higher Education, 6(4), 326-339.

Moore, M. G. (Ed.). (2013). Handbook of distance education. Routledge.

Muilenburg, L. Y., \& Berge, Z. L. (2005). Student barriers to online learning: A factor analytic study. Distance education, 26(1), 29-48.

Murray, M. C., Pérez, J., Geist, D., \& Hedrick, A. (2012). Student interaction with online course content: Build it and they might come. Journal of Information Technology Education: Research, 11(1), 125-140.

Nandi, D., Hamilton, M., \& Harland, J. (2015). What factors impact student-content interaction in fully online courses. International Journal of Modern Education and Computer Science, 7, 28-35.

Nicol, D. J., \& Macfarlane-Dick, D. (2006). Formative assessment and self-regulated learning: A model and seven principles of good feedback practice. Studies in Higher Education, 31(2), 199-218.

Nylund, K. L., Asparouhov, T., \& Muthén, B. O. (2007). Deciding on the number of classes in latent class analysis and growth mixture modeling: A Monte Carlo simulation study. Structural Equation Modeling, 14(4), 535-569.

Nylund-Gibson, K., \& Choi, A. Y. (2018). Ten frequently asked questions about latent class analysis. Translational Issues in Psychological Science, 4(4), 440-461. http://dx.doi.org/10.1037/tps0000176

Orona, G. A., Li, Q., McPartlan, P., Bartek, C., \& Xu, D. (2020). Surveying online interaction: Relating college instructor characteristics and perceptions to online practices. Working paper, Online Learning Research Center, University of California, Irvine. https://drive.google.com/file/d/1I056EpVZIK7WoFpoy_UROJoGitkG2fiz/view

Partlow, K. M., \& Gibbs, W. J. (2003). Indicators of constructivist principles in Internet-based courses. Journal of Computing in Higher Education, 14(2), 68.

PCAST. (2012). Engage to excel: Producing one million additional college graduates with degrees in science, technology, engineering, and mathematics. Washington, DC.

Perera, H. N., Calkins, C., \& Part, R. (2019). Teacher self-efficacy profiles: Determinants, outcomes, and generalizability across teaching level. Contemporary Educational Psychology, 58, 186-203.

Richardson, J., \& Swan, K. (2003). Examing social presence in online courses in relation to students' perceived learning and satisfaction. Journal of Asynchronous Learning Network 7(1), 68-88. 10.24059/olj.v7i1.1864

Robinia, K. A., \& Anderson, M. L. (2010). Online teaching efficacy of nurse faculty. Journal of Professional Nursing, 26(3), 168-175. 
Rutherford, T., Long, J. J., \& Farkas, G. (2017). Teacher value for professional development, self-efficacy, and student outcomes within a digital mathematics intervention. Contemporary Educational Psychology, 51, 22-36.

Shieh, R. S., Gummer, E., \& Niess, M. (2008). Perspectives of the instructor and the students. TechTrends, 52(6), 61-68.

Silverthorn, D. U., Thorn, P. M., \& Svinicki, M. D. (2006). It's difficult to change the way we teach: Lessons from the integrative themes in physiology curriculum module project. Advances in Physiology Education, 30(4), 204-214. https://doi.org/10.1152/advan.00064.2006

Singer, S. R., Nielsen, N. R., \& Schweingruber, H. A. (2012). Discipline-based education research. Washington, DC.

Stains, M., Harshman, J., Barker, M. K., Chasteen, S. V., Cole, R., DeChenne-Peters, S. E., Eagan, M. K., Esson, J. M., Knight, J. K., Laski, F. A., Levis-Fitzgerald, M., Lee, C. J., Lo, S. M., McDonnell, L. M., McKay, T. A., Michelotti, N., Musgrove, A., Palmer, M. S., Plank, K. M., ... Young, A. M. (2018). Anatomy of STEM teaching in North American universities. Science, 359(6383), 1468-1470. https://doi.org/10.1126/science.aap8892

Tirrell, T., \& Quick, D. (2012). Chickering's seven principles of good practice: Student attrition in community college online courses. Community College Journal of Research and Practice, 36(8), 580-590.

Tschannen-Moran, M., \& Hoy, A. W. (2001). Teacher efficacy: Capturing an elusive construct. Teaching and Teacher Education, 17(7), 783-805.

Tschannen-Moran, M., Hoy, A. W., \& Hoy, W. K. (1998). Teacher efficacy: Its meaning and measure. Review of Educational Research, 68(2), 202-248.

Vang, K., Martin, F., \& Wang, C. (2020). Examining community college faculty perceptions of their preparedness to teach online. Journal of Applied Research in the Community College, 27(1), 45-63.

Walters, S., Grover, K. S., Turner, R. C., \& Alexander, J. C. (2017). Faculty perceptions related to teaching online: A starting point for designing faculty development initiatives. Turkish Online Journal of Distance Education, 18(4), 4-19.

Wang, H. (2005). A qualitative exploration of the social interaction in an online learning community. International Journal of Technology in Teaching and Learning, 1(2), 79-88.

$\mathrm{Xu}, \mathrm{D} .$, \& Xu, Y. (2019). The promises and limits of online higher education: Understanding how distance education affects access, cost, and quality. American Enterprise Institute.

Yildirim, T. M., \& Eslen-Ziya, H. (2020). The differential impact of COVID-19 on the work conditions of women and men academics during the lockdown. Gender, Work \& Organization. https://doi.org/10.1111/gwao.12529

Zhang, L. (2006). Effectively incorporating instructional media into web-based information literacy. The Electronic Library, 24(3), 294-306. 
Table A1

\section{Appendix A}

Latent Class Analysis Fit Indexes

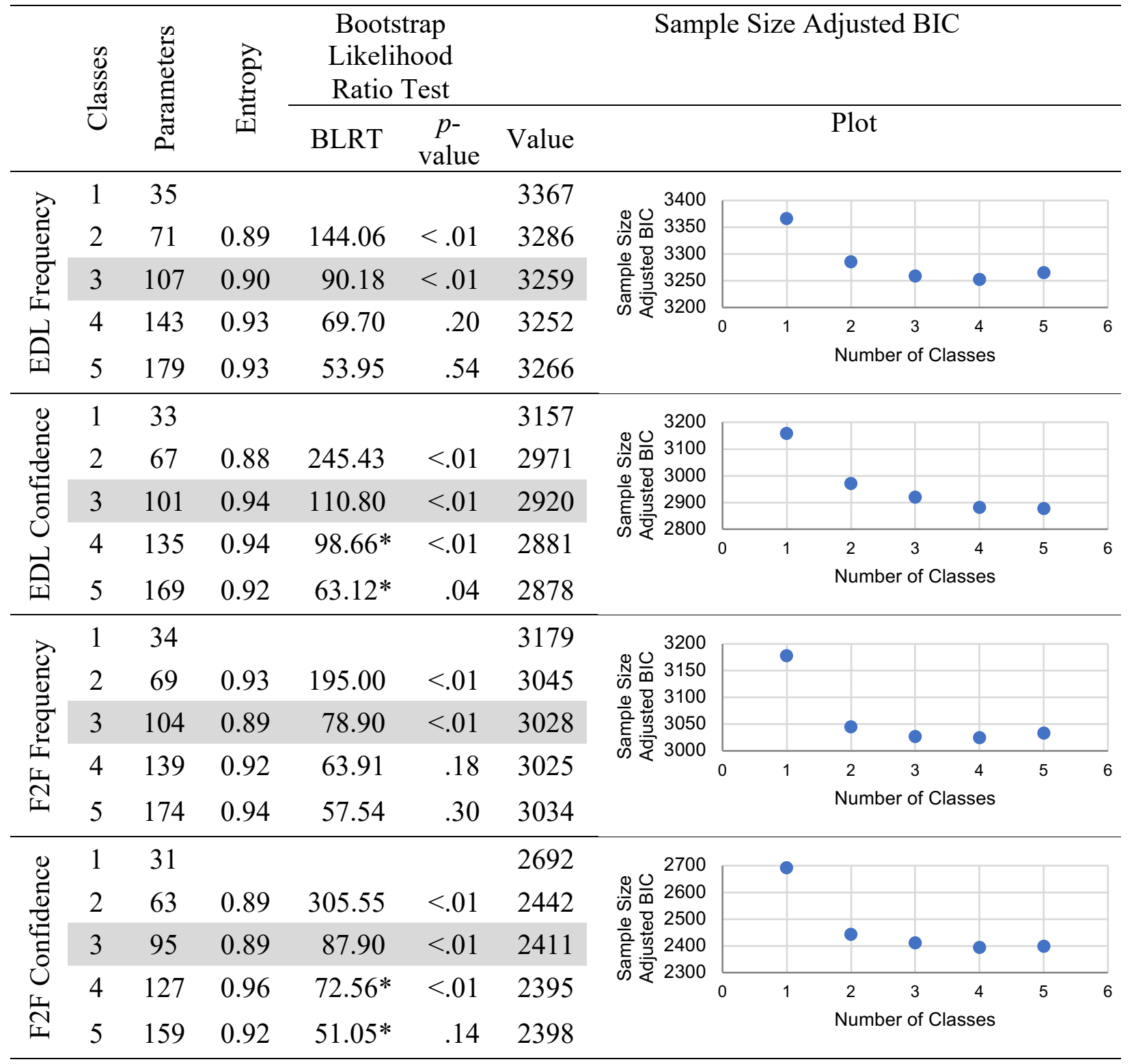

Note. *The best loglikelihood value was not replicated; therefore, the solution is not trustworthy. $\mathrm{N}=137$ 